\title{
Artigo
}

\section{Agroecologia: Conceitos, princípios e sua multidimensionalidade}

\author{
Luciano Zanetti Pessôa Candiotto
}

\begin{abstract}
Resumo
A proposta de discutir o conceito de agroecologia, considerando princípios e concepções, com base em publicações de pesquisadores e em documentos de instituições vinculadas a questão alimentar, agrária e ambiental, norteou a elaboração deste artigo. Além da clássica discussão sobre a agroecologia enquanto ciência, prática e movimento social, também são abordados os seguintes aspectos da agroecologia: sua multidimensionalidade; seu caráter multidisciplinar; sua multiescalaridade; e sua possível contribuição em um processo de transformação social. Defende-se a ideia de que a agroecologia é uma agricultura praticada por camponeses, pois apesar de ter nascido enquanto uma ciência, é resultante de diversas práticas sócio-culturais populares. Do ponto de vista escalar e geográfico, a agroecologia tem se materializado, sobretudo, em estabelecimentos agropecuários, que preferimos denominar Núcleos de Vida e Gestão Familiares (NVGF), e que fazem parte da escala geográfica denominada nanoterritorial (SOUZA, 2013). No entanto, ações de apoio e fortalecimento à agroecologia também têm se manifestado em outras escalas, como a microlocal, municipal, estadual, nacional, internacional etc. Considerando que, em torno do termo agroecologia, existe um amplo campo de disputas e de relações de poder, levando a um risco de cooptação da agroecologia por instituições e empresas vinculadas à lógica capitalista, entende-se que é preciso lutar por ela, defendendo-a enquanto uma possível ferramenta para a soberania alimentar e territorial e, quem sabe, para o fortalecimento da autonomia camponesa.
\end{abstract}

Palavras-chave: Agroecologia; multidimensionalidade; políticas; soberania alimentar; camponês.

\section{Agroecology: Concepts, principles, and their multidimensionality}

\begin{abstract}
The discussion of the concept of agroecology, considering its principles and concepts, based on publications by researchers and documents from institutions linked to food, agrarian and environmental
\end{abstract}


issues, is the aim of this paper. In addition to the classical discussion of agroecology as a science, practice and social movement, the following aspects of agroecology are also addressed: its multidimensionality; its multidisciplinary character; its multiscalarity; and its possible contribution to a process of social transformation. It defends the idea that agroecology is an agriculture practiced by peasants, because despite being born as a science, it is the result of several popular socio-cultural practices. From a scale and geographic point of view, agroecology has materialized, above all, in stockbreeding holding, which we prefer to call Family Life and Management Nucleus (FLMN), and that are part of the geographical scale called nano-territorial (SOUZA, 2013). However, actions to support and strengthen agroecology have also manifested themselves at other scales, such as local, regional, national, international etc. Considering that, around the term agroecology, there is a wide field of disputes and power relations, leading to a risk of cooptation of agroecology by institutions and companies linked to capitalist logic, it is understood that it is necessary to fight for it, defending itself as a possible tool for food and territorial sovereignty and, who knows, for the strengthening of peasant autonomy.

Keywords: Agroecology; multidimensionality; policies; food sovereignty; peasants.

\title{
Agroecología: Conceptos, principios y su multidimensionalidad
}

\begin{abstract}
Resumen
La propuesta de discutir el concepto de agroecología, considerando principios y conceptos, basada en publicaciones de investigadores y documentos de instituciones vinculadas a la temática alimentaria, agraria y ambiental, orientó la elaboración de este artículo. Además de la discusión clásica de la agroecología como ciencia, práctica y movimiento social, también se abordan los siguientes aspectos de la agroecología: su multidimensionalidad; su carácter multidisciplinario; su multiescalaridad; y su posible contribución a un proceso de transformación social. Se defiende la idea de que la agroecología es una agricultura practicada por campesinos, pues a pesar de haber nacido como ciencia, es el resultado de varias prácticas socioculturales populares. Desde un punto de vista escalar y geográfico, la agroecología se ha materializado, sobre todo, en los establecimientos agrícolas, que preferimos llamar Núcleos de Vida y Gestión Familiar (NVGF), e que forman parte de la escala geográfica denominada nanoterritorial (SOUZA, 2013). Sin embargo, las acciones de apoyo y fortalecimiento de la agroecología también se han manifestado en otras escalas, como la local, regional, nacional, internacional etc. Considerando que, en torno del término agroecología, existe un amplio campo de disputas y relaciones de poder, lo que conlleva un riesgo de cooptación de la agroecología por parte de instituciones y empresas vinculadas a la lógica capitalista, se entiende que es necesario luchar por ella, defendiéndola como una posible herramienta para la soberanía alimentaria y territorial y, quizá, para el fortalecimiento de la autonomía campesina.
\end{abstract}

Palabras clave: Agroecología; multimensionalidad; políticas; soberanía alimentaria; campesinos. 


\section{Introdução}

O tema da agroecologia tem despertado o interesse de pesquisadores ${ }^{1}$, organizações ligadas a agricultores, instituições públicas e outros setores. A palavra agroecologia tem sido utilizada em diversas ocasiões, como publicações científicas, políticas públicas (normas e ações), disciplinas e cursos acadêmicos, movimentos sociais e na própria linguagem popular, seja de agricultores ou de consumidores. Como a agroecologia é, no meio acadêmico, um conceito polêmico, buscou-se, neste artigo, analisá-lo e discuti-lo, considerando seus princípios e evidenciando sua multidimensionalidade. Conforme Wezel et al. (2009), a definição de agroecologia é, historicamente, marcada por confusões.

Como procedimentos metodológicos, foram analisadas publicações (artigos, livros, teses e dissertações) sobre o tema, além de informações presentes no site da Organização das Nações Unidas para Agricultura e Alimentação (FAO)²; em documentos de instituições internacionais de apoio a agroecologia, como o CIDSE (2018), a Declaração de Nyéléni - documento resultante do Fórum Internacional sobre Agroecologia (2015) -, entre outras. Também foram consultadas publicações e outras referências produzidas no Brasil, que tratam do conceito e dos princípios da agroecologia.

A partir de publicações científicas (GLIESSMAN, 2018; VAN DER PLOEG, 2011; WEZEL et al., 2009³), de dados do site da FAO, e de outros documentos e eventos, como o último Congresso Latino-americano sobre agroecologia (SOCLA) ${ }^{4}$, percebe-se que há um destaque para a agroecologia enquanto: 1) ciência; 2) prática e; 3) movimento social.

\footnotetext{
${ }^{1}$ A partir de um levantamento na base de publicações científicas Web of Science sobre a palavra agroecology, Wezel et al. (2009), apontam que, em 1991, existiam somente 6 menções, enquanto, em 2007, 141. Ao atualizar as menções ao termo agroecology presentes em 17 de novembro de 2020 na base Web of Science, verificamos 436 menções em títulos de publicações científicas. Ao pesquisar no item "todos os campos", foram 3.200 menções, enquanto no item "tópicos", 2.000 menções.

2 Para maiores informações consultar <www.fao.org/agroecology $\rangle$.

3 "Today, the term 'agroecology' means either a scientific discipline, agricultural practice, or political or social movement" (p. 503).

4 O VII Congresso Latino-americano de agroecologia promovido pela SOCLA em 2018, teve como título "Agroecología: ciencia, práctica y movimiento social para alcanzar Soberanía Alimentaria”.
} 
Não obstante, com base na literatura sobre o tema, com ênfase em autores latinoamericanos, bem como em nossas reflexões, percebe-se que existem outros elementos relevantes quando se fala em agroecologia. Entre eles, estão: 4) a sua multidimensionalidade, pois, a partir da agricultura e da produção de alimentos, a agroecologia envolve as dimensões espacial, alimentar, ecológica, econômico-produtiva, político-organizativa, técnica e sócio-cultural; 5) a sua multi ou interdisciplinaridade, pelo fato de diversas disciplinas científicas terem algum tipo de interesse ou de relação com o tema; 6) a sua multiescalaridade, por ser um fenômeno que é praticado em áreas de cultivo (agroecossistemas) e estabelecimentos agropecuários ${ }^{5}$ (em escala nanoterritorial, para usar o termo de Souza [2013]), perpassando comunidades rurais, municípios, estados, países, e chegando até a escala global, através do debate sobre o sistema alimentar mundial, sobre a resiliência climática e sobre o futuro da agricultura e da alimentação; 7) o seu potencial transformador, na relação entre sociedade e natureza e nos valores éticos que fundamentam essa relação; no questionamento de limites da ciência pautada na fragmentação de conhecimentos; e, na luta por justiça ambiental, que, necessariamente, envolvem justiças sociais e redução da degradação ambiental. Esses sete elementos serão discutidos no artigo.

\section{O conceito de agroecologia}

No plano histórico, Wezel et al. (2009) enfatizam que a agroecologia surgiu no meio científico, tendo alguns de seus princípios delineados a partir da década de 1930, apesar do primeiro livro com o título "agroecologia” (Agrarökologie) ter sido escrito em 1965 por Tischler. Esses autores elencam uma lista das principais obras relacionadas a

\footnotetext{
${ }^{5}$ No Brasil, o Instituto Brasileiro de Geografia e Estatística (IBGE), utiliza o conceito de estabelecimento agropecuário, para se referir a unidades de produção ou exploração dedicada, total ou parcialmente, a atividades agropecuárias, florestais e aquícolas, onde os produtos são comercializados ou diretamente consumidos pelos agricultores (IBGE, 2017).
} 
agroeocologia e discutem dois grandes períodos, sendo a "old age", da década de 1930 à de 1960; e o período de expansão da agroecologia, a partir da década de 1970.

Dois autores são considerados as maiores referências da agroecologia, devido a sua ampla trajetória acadêmica vinculada ao tema: Miguel Altieri e Stephen Cliessman. A primeira obra de Altieri sobre o tema, é o livro intitulado "Agroecology", de 1983. Entre suas diversas publicações, destaca-se o livro "Agroecology: the science of sustainable agriculture agriculture”, de 1995. Já a primeira publicação de Gliessman sobre o tema foi “Memorias del Seminario regional sobre la agricultura agricola tradicional”, de 1978. Além de diversos artigos, os livros "Agroecology: ecological processes in sustainable agriculture", de 1997 e "Agroecology: the ecology of sustainable food systems", de 2007, são importantes obras deste pesquisador (WEZEL et al., 2009).

Altieri e Gliessman entendem que o agroecossistema é a unidade de desenvolvimento das práticas agroecológicas; vinculam a agroeocologia com a ideia de uma agricultura sustentável, e; enfatizam a importância do uso de insumos orgânicos oriundos do próprio agroecossistema. Em 1995, Altieri definiu a agroecologia como a aplicação de conceitos e princípios ecológicos no desenho e manejo de agroecossistemas sustentáveis. Em 2000, ampliou esse conceito, ao definir a agroecologia como uma "nova abordagem que integra os princípios agronômicos, ecológicos e socioeconômicos à compreensão e avaliação do efeito das tecnologias sobre os sistemas agrícolas e a sociedade como um todo" (ALTIERI, 2000, p. 18).

Em 2001, Gliessman afirmou que a agroecologia "é o estudo de processos econômicos e de agroecossistemas" mas também "um agente para as mudanças sociais e ecológicas complexas que tenham necessidade de ocorrer no futuro a fim de levar a agricultura para uma base verdadeiramente sustentável” (p. 56), indicando que a agroecologia é uma ciência, que por sua vez, possui um papel transformador em termos sociais e ecológicos. De forma muito similar ao conceito de Altieri (1995), Gliessman (2001), também entendia a agroeocologia enquanto a aplicação de conceitos e princípios ecológicos no 
desenho e manejo de sistemas alimentares sustentáveis ${ }^{6}$. Em livro escrito por Gliessman em 2015, o próprio título identifica a agroecologia como a ecologia de sistemas alimentares sustentáveis (Agroecology: The ecology of sustainable food systems).

Mais recentemente, em editorial do periódico "Agroecology and sustainable food systems”, com o título definindo agroecologia (Defining Agroecology), Gliessman (2018, p. 599-600) faz um rápido resgate acerca da trajetória desse conceito. Considerando a relevância deste pesquisador e a atualidade da publicação, o Box 1 apresenta uma síntese interpretativa da visão de Gliessman (2018).

\footnotetext{
${ }^{6}$ Ao referir-se ao período de emergência da agroecologia, iniciado no início da década de 1980, Gliessman (2018, p. 599) destaca que a definição mais comum de agroecologia era: "the application of ecological concepts and principles to the design and management of sustainable agroecosystems, or the science of sustainable agriculture". Esta definição é atribuída a Altieri e Gliessman, em publicações distintas, pelo próprio Gliessman.
} 


\section{BOX 1 - Definindo a agroecologia}

Durante a década de 1980, o foco da agroecologia estava na escala do estabelecimento agropecuário (farm) ou do agroecossistema (farm system). Isso levou a substituição de insumos e práticas da agricultura convencional, sobretudo os fertilizantes oriundos de combustíveis fósseis, e contribuiu para a certificação de sistemas orgânicos de produção e para a diversificação produtiva. No final da década de 1990, Francis et al. (2003), ampliaram a escala da agroecologia, propondo que ela seria a ecologia de todo o sistema alimentar (the ecology of the entire food system). Essa definição, inclui todos os aspectos e envolvidos com o sistema alimentar. Gliessman (2018), destaca a importância da redução de intermediários nas relações entre agricultores e consumidores, potencializando mercados mais justos.

Gliessman (2018, p. 599), apresenta a seguinte definição para a agroecologia:

Agroecologia é a integração de pesquisas, educação, ação e mudanças que propiciam sustentabilidade para todas as partes do sistema alimentar: ecológica, econômica e social. Ela é transdisciplinar, pois valoriza diferentes formas de conhecimentos e experiências direcionadas para a transformação do sistema alimentar. Ela é participativa, pois requer envolvimento de todos os sujeitos, de agricultores até consumidores. Ela é orientada por ações, pois confronta estruturas econômicas e políticas do atual sistema alimentar através de estruturas sociais e ações políticas alternativas. Sua abordagem é baseada no pensamento ecológico, onde uma compreensão holística sobre a sustentabilidade dos sistemas alimentares em vários níveis se faz necessária. ${ }^{7}$

Tal definição ressalta a multidimensionalidade da agroecologia, ao envolver a integração entre pesquisa, educação, ação (prática), na busca por mudanças ecológicas, econômicas e sociais que conduzam à sustentabilidade em todo o sistema alimentar. O caráter transdisciplinar, a necessidade de participação de agricultores, consumidores e outros sujeitos, o confronto às estruturas de poder econômico e político do atual sistema alimentar industrial, através de estruturas sociais alternativas e da ação política, bem como seu embasamento a partir de um pensamento ecológico e holístico, também são destacados no conceito proposto por Gliessman.

Assim, a transformação da agricultura através da agroecologia requer uma abordagem que considere, simultaneamente, os três grandes aspectos que permeiam a agroecologia:

Científico: necessidade de ampliação dos conhecimentos sobre as relações ecológicas entre as espécies agrícolas domesticadas; entre essas espécies e o ambiente biofísico, sobretudo o solo enquanto ecossistema; e, entre espécies agrícolas e naturais dos ecossistemas.

Prático: necessidade de práticas agrícolas efetivas e inovadoras nas áreas onde se desenvolve a agroecologia - ou seja, nos agroecossistemas - , que satisfaçam nossas necessidades alimentares do presente e que estejam atentas às necessidades do futuro. A troca de conhecimentos empíricos e a aproximação entre aqueles que produzem conhecimentos (agricultores, cientistas, técnicos) e aqueles que aplicam os conhecimentos (sobretudo agricultores), é fundamental para o avanço das práticas agroecológicas;

Mudanças sociais: necessidade de mudanças nas formas como os humanos se relacionam com a alimentação/comida; nos sistemas econômicos e sociais que determinam a distribuição dos alimentos; e, nas formas como a comida interfere nas relações de poder entre populações, classes e países. Esse aspecto, engloba a busca pela segurança alimentar para todos, bem como os meios para se ativar e sustentar essas mudanças.

Apesar de todos esses aspectos serem críticos, é a integração entre eles que permitirá construir a estrutura para se alcançar a transformação do sistema alimentar.

Fonte: Gliessman (2018). Elaborado pelo autor.

\footnotetext{
7 "Agroecology is the integration of research, education, action and change that brings sustainability to all parts of the food system: ecological, economic, and social. It's transdisciplinary in that it values all forms of knowledge and experience in food system change. It's participatory in that it requires the involvement of all stakeholders from the farm to the table and everyone in between. And it is action-oriented because it confronts the economic and political power structures of the current industrial food system with alternative social structures and policy action. The approach is grounded in ecological thinking where a holistic, systems-level understanding of food system sustainability is required."
}

AMBIENTES. Volume 2, Número 2, 2020, pp. 25-75. ISSN: 2674-6816

DOI: https://doi.org/10.48075/amb.v2i2.26583 
Outro pesquisador que tem debatido a agroecologia, considerando sua importância para a agricultura camponesa é Jan Douwe van der Ploeg. Por meio do que denomina condição camponesa, van der Ploeg (2011) ressalta a luta constante dos camponeses do mundo por autonomia, entendendo que eles são fundamentais para a construção e fortalecimento da agroecologia. De forma similar a Gliessman (2018), Wezel et al. (2009) e outros autores, van der Ploeg (2011) entende a agroecologia enquanto ciência, prática e movimento social. Contudo, no plano científico, ele ressalta que a agroecologia é uma teoria crítica radical; no plano prático, que as práticas agroecológicas são fundamentais para o próprio avanço da ciência da agroecologia; enquanto no plano dos movimentos sociais, ela engloba (ou deveria englobar), outros sujeitos para além dos agricultores e cientistas.

Agroecologia é uma teoria crítica. Ela compõe uma crítica radical sobre as dimensões ecológica, agronômica, social e econômica relacionadas ao crescimento dos sistemas agrícolas industrializados no mundo e dos impactos dramáticos destes sistemas. [...] Agroecologia é uma prática. É a prática daqueles que estão aplicando, explícita ou implicitamente, reflexões alternativas que são acumuladas e elaboradas, em seguida, no nível da teoria. [...] Agroecologia é um movimento social. Um movimento, não somente daqueles que estão diretamente envolvidos nas práticas e/ou nas teorias sobre agroecologia; ela deve envolver diversos atores, isto é, todos os interessados em um alimento bom e seguro, em um ambiente limpo, na justiça social e em relações bem equilibradas entre cidade e campo (VAN DER PLOEG, 2011, p. 47). ${ }^{8}$

Wezel et al. (2009) ressaltam que existem diferentes interpretações sobre a agroecologia, no meio científico, no contexto das práticas e, também, entre os movimentos sociais. Isso tem conduzido a uma utilização crescente do termo, bem como a possíveis

\footnotetext{
8 "Agro-ecology is a critical theory. It composes a radical critique on the ecological, agronomic, social and eco-nomic dimensions of the increasingly industrialized agricultural systems of the world and on the often-dramatic impact these systems are having. [...] Agro-ecology is a practice. It is the practice of those who are applying (explicitly or implicitly) the alternative insights that are accumulated (and elaborated further) at the level of theory. [...] Agroecology is a social movement. It is a movement, not only of those directly involved in the practice and/or theory of agro-ecology; it might embrace far more actors, i.e. all those who are interested a good and safe food, in a clean environment, in social justice and in well-equilibrated relations between town and countryside."
} 
distorções, como o clássico caso do equivocado entendimento de que a agroeocologia é um sinônimo de agricultura orgânica, produção orgânica ou produto orgânico. 9

No entanto, diversos movimentos sociais camponeses, como a Via Campesina, o Movimento Agroecológico da América Latina e do Caribe (MAELA), entre outros, através da realização do Fórum Internacional de Agroecologia em 2015, que teve como documento final a Declaração de Nyéléni $(2015)^{10}$, bem como da elaboração da publicação da Organização Amigos da Terra, intitulada "Agroecología: innovaciones para sistemas agrícolas y alimentarios sustentables" (2018) $)^{11}$, que foi escrito como uma clara resposta contestando os princípios e a concepção de agroecologia definidos pela ONU através da FAO, têm procurado afirmar a agroecologia como uma bandeira da luta camponesa, que engloba, sobretudo, a soberania alimentar ${ }^{12} \mathrm{e}$, consequentemente, territorial.

O objetivo da Declaração de Nyéléni (2015, p. 3), foi construir e estabelecer "uma compreensão comum sobre a Agroecologia como elemento-chave na construção da Soberania Alimentar, e para desenvolver estratégias conjuntas para promover a Agroecologia e, defendê-la da cooptação". No documento final da Declaração, foram definidas estratégias para o fortalecimento da agroecologia (p. 6-8).

Conforme alertado por Giraldo e Rosset (2016 e 2017) e por Rosset e Altieri (2018), nos últimos anos, tem havido uma polarização na interpretação sobre os princípios e objetivos da agroecologia, por parte de instituições oficiais como a $\mathrm{FAO}^{13}$ e, de outro lado, por movimentos sociais, agricultores, ativistas etc.

\footnotetext{
9 Esse debate não será aprofundado aqui. Porém, a sequência do artigo demonstrará que percebemos a agroecologia como algo bem mais complexo que a produção orgânica ou, simplesmente, os produtos orgânicos.

${ }_{10} \mathrm{O}$ documento resultante do referido Fórum pode ser acessado em <http://www.foodsovereignty.org/wpcontent/uploads/2015/10/NYELENI-2015-PORTUGUES-WEB.pdf>.

11 documento resultante do referido Fórum pode ser acessado em $<$ https://www.foei.org/es/recursos/publicaciones/agroecologia-innovaciones-para-sistemas-agricolas-yalimentarios-sustentables>.

${ }^{12}$ Ver Stédile e Carvalho (2010) e van der Ploeg (2014).

${ }^{13}$ A partir da década de 2010, a Organização das Nações Unidas para Agricultura e Alimentação (FAO), tem organizado eventos e publicações que reconhecem a importância da agroecologia, como o Simpósio Internacional sobre agroecologia para a segurança alimentar e nutricional de 2014, o Relatório do Painel de experts em segurança alimentar e nutricional (HLPE, 2016), e Simpósios regionais em 2018 na África, Ásia, América Latina e Europa.
} 
O lado institucional entende a agroecologia como um conjunto de ferramentas adicionais para uma produção industrial de alimentos, que passou a ser questionada devido às emissões de gases do efeito estufa e que está sofrendo uma queda de produtividade e uma alta dos custos de produção devido à degradação ecológica e suas consequências nos recursos produtivos, como o solo, a água, a biodiversidade etc. Consideram as ferramentas agroecológicas como meios para tornar esse "modelo dominante" mais sustentável, sem questionar as relações de poder subjacentes e a estrutura dos monocultivos em grande escala. [...] e outro lado, composto por diversos cientistas, ativistas e militantes, agricultores ecológicos, ONG e movimentos sociais, entende a agroecologia como uma alternativa à produção industrial de alimentos e como uma alavanca para a transformação do sistema alimentar em algo melhor para as pessoas e o ambiente (ROSSET; ALTIERI, 2018, p. 24) ${ }^{14}$. (grifo nosso).

Nesse sentido, é possível afirmar que a agroecologia (termo e princípios) vêm sendo disputada por instituiçõos do setor alimentar como a FAO; instituiçõos representantes de produtores e certificadoras de produtos orgânicos, como a IFOAM (Federação Internacional dos Movimentos de Agricultura Orgânica); governos locais, regionais e nacionais, por meio de políticas públicas; políticos; empresas que comercializam produtos orgânicos; e camponeses, seus movimentos sociais e organizações de apoio. Muitas vezes, essas disputas não são claras ou explícitas, confundindo a percepção sobre quais são os interesses e intencionalidades de cada grupo ou instituição. Alguns princípios da agroecologia são usados por todos esses sujeitos, como a defesa de uma produção livre de agrotóxicos e transgênicos (produtos orgânicos) e o discurso sobre cuidados com elementos da natureza (solos, água, ecossistemas). Todavia, outros princípios têm sido defendidos exclusivamente por camponeses e suas organizações, como a garantia de sobe-

\footnotetext{
${ }^{14} \mathrm{El}$ bando institucional la entiende como un conjunto de herramientas adicionales para una producción industrial de alimentos que ha sido puesta en entredicho por sus emisiones de gases de efecto invernadero y que está sufriendo una caída de la productividad y una subida de los costos de producción debido a la degradación ecológica que provoca en los recursos productivos como el suelo, el agua, la biodiversidad funcional, etc. Consideran las herramientas agroecológicas como medios para lograr que este "modelo dominante" sea un ápice más sostenible, sin cuestionar ni las relaciones de poder subyacentes, ni la estructura de los monocultivos a gran escala. [... ] el otro bando, compuesto por numerosas científicas, activistas y militantes, agricultores ecológicos, ONG y movimientos sociales, entiende la agroecología como una alternativa a la producción industrial de alimentos y como una palanca para la transformación del sistema alimentario en algo mejor para las personas y para el medio ambiente.
} 
rania alimentar (que é mais ampla que a segurança alimentar) e territorial para os camponeses; a priorização de mercados justos, que permitam o acesso a alimentos orgânicos por parte dos pobres, e não somente dos ricos; e, finalmente, a efetivação de transição do modelo de agricultura convencional predominante (o agronegócio), para um novo sistema alimentar.

Além do conceito de agroecologia envolver ciência, prática e movimento social, ele abrange, também, múltiplas dimensões, que serão discutidas na sequência do artigo. Ao definir os princípios da agroecologia, a Organização Não-governamental (ONG) CIDSE, indica essa multidimensionalidade, através de quatro grandes vertentes:

1) Ambiental: a agroecologia melhora a sinergia entre os elementos dos agrossistemas e os sistemas alimentares; contribui para a vida do solo, crescimento das plantas e biodiversidade; otimiza ciclos naturais, que reciclam nutrientes; elimina a dependência de insumos sintéticos externos; contribui para a resiliência climática e redução da emissão de gases estufa, através da redução do uso de combustíveis fósseis e da fixação de carbono nos solos;

2) Cultural e social: valoriza conhecimentos produtivos, alimentares e espirituais tradicionais de comunidades locais; possibilita a troca de conhecimentos entre agricultores e, destes, com pesquisadores e com a população urbana; respeita a diversidade cultural, as mulheres e os jovens; defende os Sistemas Participativos de Garantia (SPG);

3) Econômica: promove redes de comercialização e distribuição de alimentos curtas e justas; contribui para a subsistência das famílias camponesas e para os mercados locais; se pauta em uma economia social e solidária; melhora e diversifica a renda dos agricultores; se pauta em preços justos para os consumidores; aumenta a autonomia das comunidades;

4) Política: prioriza as necessidades dos camponeses; transfere o controle de sementes, água e territórios para as comunidades locais; promove a participação e novas estruturas de governança, visando mudar as relações de poder; luta 
pela ampliação de investimentos públicos; incentiva a auto-organização e a gestão coletiva em diferentes níveis escalares (do local ao global) (CIDSE, 2018)15.

No Brasil, a Associação Brasileira de Agroecologia (ABA $)^{16}$, junto com a Articulação Nacional de Agroecologia (ANA) ${ }^{17}$, são as principais instituições que agregam pesquisadores, técnicos, ativistas e outros adeptos do tema. Enquanto a ABA se caracteriza como uma instituição científica, responsável pela Revista Brasileira de Agroecologia, pela Revista Cadernos de Agroecologia e pelos onze Congressos Brasileiros de Agroecologia realizados até o momento, a ANA é composta por instituições diversas, com destaque para Organizações Não-governamentais (ONGs), associações de agricultores e movimentos sociais.

A ABA utiliza o seguinte conceito de agroecologia:

Agroecologia é entendida como enfoque científico, teórico, prático e metodológico, com base em diversas áreas do conhecimento, que se propõe a estudar processos de desenvolvimento sob uma perspectiva ecológica e sociocultural e, a partir de um enfoque sistêmico - adotando o agroecossistema como unidade de análise - apoiar a transição dos modelos convencionais de agricultura e de desenvolvimento rural para estilos de agricultura e de desenvolvimento rural sustentável (ABA, s/d, s/p. $)^{18}$.

Portanto, as informações apresentadas até o momento, já indicam a complexidade e multidimensionalidade da agroecologia. A sequência do artigo ampliará esse debate.

\section{A agroecologia enquanto ciência}

No processo de construção da agroecologia destaca-se sua dimensão científica, de modo que ela é trabalhada por diversos autores como uma disciplina científica ou como parte de uma nova ciência, que integraria conhecimentos da Agronomia, da Ecologia e

\footnotetext{
15 O documento completo sobre os princípios da agroecologia está disponível em <https://www.cidse.org/pt/2018/04/03/the-principles-of-agroecology/>.

${ }^{16}$ Mais informações estão disponíveis em <https://aba-agroecologia.org.br/>.

${ }_{17}$ Mais informações estão disponíveis em <https://agroecologia.org.br/>.

${ }^{18}$ Disponível em <https://aba-agroecologia.org.br/sobre-a-aba-agroecologia/sobre-a-aba/> .
} 
de outras áreas do conhecimento. Todavia, a maior parte da produção científica ligada a agroecologia, até o momento, diz respeito a questões agronômicas.

Do ponto de vista etimológico, agroecologia significa a junção entre Ecologia e Agronomia, ou seja, entre duas ciências. Ela corresponde, portanto, à ecologia dos sistemas agrícolas, e tem como principal unidade de análise o agroecossistema (GLIESSMAN, 2001).

Wezel et al. (2009) enfatizam que a agroecologia surge no meio científico, consolidando-se enquanto uma disciplina científica na década de $1970^{19}$. Contudo, a partir da década de 1980, a agroecologia emerge também como um movimento (social) e um conjunto de práticas ${ }^{20}$.

Apesar de surgir a partir da Agronomia e da Ecologia, a agroecologia foi ganhando adeptos de outras áreas do conhecimento, tornando-se uma ciência multidisciplinar, de modo que Wezel et al. (2009) apontam que, a partir da década de 1980, a agroeocologia foi se estabelecendo com base em métodos holísticos voltados ao estudo de agroecossistemas. Contudo, a agroecologia foi avançando em termos de escala geográfica, de modo que, da escala do agroecossistema ou do estabelecimento agropecuário, ela ampliou seu escopo até a escala global da produção, distribuição e consumo de alimentos.

O documento do Comitê de experts de alto nível em segurança alimentar e nutricional da ONU (HPLE, 2016), órgão vinculado a FAO, com base em uma compilação de referências bibliográficas sobre o tema, define agroecologia, a partir de uma perspectiva científica e técnica, como a aplicação de princípios e conceitos ecológicos em sistemas alimentares, com foco nas interações entre plantas, animais, humanos e ambiente. $\mathrm{O}$ objetivo da agroecologia seria fortalecer o desenvolvimento agrícola sustentável e melhorar a segurança alimentar e nutricional para todas as pessoas, no presente e no futuro.

\footnotetext{
19 Esses autores destacam obras as publicações de Hecht (1995), Francis et al. (2003) e Gliessman (2007) como referências importantes no debate sobre a história da agroecologia.

${ }^{20}$ Em relação à agroecologia enquanto prática, discordamos de Wezel et al. (2009), pois entendemos que diversas práticas agrícolas ancestrais, inclusive milenares, se constituem enquanto práticas agroecológicas, apesar de não utilizarem necessariamente esse termo.
} 
A FAO reconhece a agroecologia enquanto uma disciplina científica, porém, apoiada em outros autores, considera algumas críticas que são feitas à ciência tradicional.

Como disciplina científica, a agroecologia não é prescritiva, pois não proporciona receitas nem pacotes técnicos. Ela se baseia na aplicação local de princípios agroecológicos básicos. [...] A escolha das práticas de gestão e as tecnologias para alcançar a agroecologia ou avançar em direção a uma transição agroecológica depende sempre da localidade específica e é moldada por um contexto social e ecológico determinado.

A ciência da agroecologia reconhece explicitamente o valor dos conhecimentos e da pesquisa participativos e de baixo para cima, promovendo: i) o estabelecimento de vínculos entre processos formais e informais de inovação; ii) a combinação de competências especializadas de um lugar com conhecimentos científicos; iii) o reconhecimento do respeito que aos agricultores, como proprietários de conhecimentos e participantes na pesquisa e na inovação (FAO, s/d). ${ }^{21}$

A citação acima, indica que, para a FAO, a agroecologia deve ser pesquisada e praticada considerando-se as especificidades ecológicas, sociais e culturais dos lugares e os ecossistemas locais. A pesquisa participativa com os agricultores também é ressaltada, indicando um certo incentivo a interação entre agricultores e pesquisadores por parte da instituição.

Altieri e Toledo (2011) entendem que a agroecologia está aportando às bases científicas para uma nova "revolução agrária" em escala mundial, visto que os sistemas de produção fundados em princípios agroecológicos, são biodiversos, resilientes, eficientes energeticamente, socialmente justos e estão fortemente vinculados à soberania alimentar. Assim, a agroecologia é tanto uma ciência como um conjunto de práticas, pois está baseada em conhecimentos e técnicas que se desenvolvem a partir dos agricultores e de

\footnotetext{
21 "Como disciplina científica, la agroecología no es prescriptiva, ya que no proporciona recetas ni paquetes técnicos. Se basa en la aplicación local de principios agroecológicos básicos. [...] La elección de las prácticas de gestión y las tecnologías para alcanzar la agroecología o avanzar hacia una transición agroecológica depende siempre de la localidad específica y se ve modelada por un contexto social y ecológico determinado. La ciencia de la agroecología reconoce explícitamente el valor de los conocimientos y la investigación participativos y de abajo arriba y promueve: i) el establecimiento de vínculos entre procesos de innovación formales e informales; ii) la combinación de las competencias especializadas del lugar con conocimientos científicos; iii) el reconocimiento del respeto que se debe a los agricultores como propietarios de conocimientos y partícipes en la investigación y la innovación." Retirado do site da FAO <www.fao.org/agroecology $>$.
} 
seus processos de experimentação. A relação entre prática e ciência dentro da agroecologia também é ressaltada por Casado et al. (2000), ao salientar que ela valoriza o manejo de agroecossistemas e dos recursos naturais pelos camponeses, ao longo da história.

Esse debate sobre a soberania alimentar e sobre a complexidade da agroecologia no plano científico, a partir de uma perspectiva multidimensional, tem sido abordado, sobretudo, por pesquisadores das ciências humanas e sociais. No entanto, o tema da agroecologia pode ser de interesse de profissionais de diversas áreas do conhecimento. Independentemente da formação, entende-se que a contribuição dos cientistas para a sistematização e avanço, teórico e empírico, da agroecologia, pode se dar através do conhecimento das experiências empíricas praticadas pelos agricultores; da interação com agricultores que possuem esses conhecimentos tradicionais, para que seja possível constatar e validar cientificamente as práticas agroecológicas. Sem as práticas populares e sua avaliação por parte dos cientistas, a agroecologia científica estaria limitada a experimentos em áreas específicas e em laboratórios.

\section{A agroecologia enquanto prática}

Desde o surgimento da agricultura, há aproximadamente 10.000 mil anos, no Período Neolítico, o homem vem buscando formas de desenvolvê-la e aperfeiçoá-la. Inicialmente, o principal objetivo dos povos da antiguidade era produzir para sua sobrevivência, ou seja, para suprir suas necessidades, de sua família e da comunidade. O modo de produção era praticado de forma rústica sem o uso de equipamentos (objetos técnicos) ou agentes químicos sintéticos, como fertilizantes e agrotóxicos. A agricultura era totalmente orgânica e estava baseada no manejo do solo com matéria orgânica, na diversidade de cultivos, priorizando o cultivo de plantas adequadas às condições de cada local.

A partir de 1750, foram criados métodos e técnicas que modificaram a agricultura mundial, como a tração animal, a substituição do pousio para o cultivo do solo durante 
todo o ano, o plantio de forragens para alimentar animais e o uso intensivo de matéria orgânica (esterco), marcando o que se denomina Primeira Revolução Agrícola. Posteriormente, por volta de 1840, inicia-se outro período, denominado Segunda Revolução Agrícola, marcado pela separação entre agricultura e pecuária; surgimento da monocultura, desenvolvimento e aplicação de máquinas e de fertilizantes sintéticos (MAZZOLENI; NOGUEIRA, 2006). Já em meados do século XX, o desenvolvimento de novas máquinas e técnicas de produção agrícola, sobretudo de tratores, sementes híbridas, fertilizantes e agrotóxicos sintéticos, permitiram a expansão de grandes áreas com uma única cultura agrícola (monoculturas), marcando a chamada Revolução Verde. A partir de então, a denominada agricultura convencional, chamada, mais recentemente, de agronegócio, tornou-se uma agricultura hegemônica. Já no final do século XX, os "avanços" na área de biotecnologia, levaram à criação de organismos geneticamente modificados, clones de animais, entre outras técnicas.

Partindo do pressuposto de que a agricultura denominada tradicional, ou seja, aquela agricultura praticada até a metade do século XIX era eminentemente uma agricultura sem o uso de fertilizantes e outros insumos químicos sintéticos, é possível, afirmar que as práticas de produção orgânicas e agroecológicas foram predominantes até a década de 1840 . Assim, a agroecologia enquanto prática é mais antiga do que a agroecologia enquanto ciência. Todavia, as práticas tradicionais que hoje podem ser denominadas de agroecológicas, não o eram até o início da agroecologia enquanto ciência ${ }^{22}$.

As práticas agroecológicas, têm sido majoritariamente desenvolvidas por agricultores de várias partes do mundo, independentemente desses agricultores serem ou não adeptos da agroecologia. Um pressuposto importante das práticas agroecológicas, é aprender com a natureza, ou seja, conhecer e aproveitar processos naturais para utilizálos no manejo dos agroecossistemas.

\footnotetext{
${ }^{22} \mathrm{~A}$ própria $\mathrm{FAO}$ afirma que as práticas relacionadas a agroecologia têm sido construídas a partir de conhecimentos locais e tradicionais provenientes de todo o mundo.
} 
Enquanto um conjunto de práticas agrícolas, a agroecologia busca formas para meIhorar os sistemas agrícolas, através do aproveitamento de processos naturais, criando interações e sinergias entre os componentes de um agroecossistema (GLIESSMAN, 2001).

As práticas agrícolas podem ser, mais ou menos agroecológicas, a partir da consideração de dois aspectos: 1) se elas usam processos ecológicos para substituir insumos externos; 2) se elas são equitativas, ecologicamente favoráveis e localmente adaptáveis e reconhecidas (WEZEL; MIGLIORINI, 2017). Tais práticas, envolvem o aproveitamento da ciclagem natural de nutrientes, a fixação biológica de nitrogênio, o controle natural de pragas e doenças, a conservação de solos e águas, a conservação de biodiversidade e o sequestro de carbono. Para tanto, a diversificação de cultivos é primordial (HLPE, 2016).

\section{A agroecologia enquanto movimento social}

De forma geral, os movimentos ecológicos, consolidados a partir da década de 1960, foram responsáveis por apontar elementos que também fazem parte da luta de movimentos agroeocológicos. O respeito à natureza e a todas as formas de vida; a importância da biodiversidade e da preservação e conservação dos ecossistemas; a denúncia da degradação ambiental causada por processos diversos de produção e consumo de mercadorias, entre outros aspectos, são bandeiras de movimentos ecológicos que, de alguma forma, são também defendidas por movimentos agroecológicos.

Os movimentos ambientalistas influenciaram a agroecologia numa perspectiva crítica. O desenvolvimento de um pensamento ecologista pautado em uma nova ética ambiental, proporcionaram os fundamentos éticos e filosóficos da agroecologia, que surgiu, desde o princípio, com uma vocação transformadora muito evidente, como uma ferramenta para pensar e organizar um futuro agrícola mais sustentável (CASADO et al., 2000). 
Além da relevância dos movimentos ecológicos, Wezel et al. (2009) apontam que os movimentos sociais que emergiram na década de 1990, sobretudo os movimentos camponeses, também têm contribuído para o crescimento dos movimentos sociais agroecológicos. Mesmo que tais movimentos - ecológicos e sociais - não utilizem necessariamente o termo agroecologia, eles costumam ter bandeiras em comum, pautadas em relações menos degradadoras da humanidade com a natureza, e na redução de desigualdades e injustiças ambientais (que, geralmente, incluem grupos humanos).

No contexto dos movimentos sociais de agricultores camponeses, a defesa da soberania alimentar e territorial; da autonomia, mesmo que relativa, de agricultores e de suas organizações coletivas; do direito a uma alimentação de qualidade para a humanidade; e a luta pela terra, são aspectos que têm sido englobados pelos objetivos e princípios da agroecologia.

[... ] a soberania alimentar se fundamenta na autonomia local, nos mercados locais, nos ciclos locais de produção e consumo, e nas redes de agricultor a agricultor que promovem inovações e ideias agroecológicas. A agroecologia não proporciona somente os princípios para alcançar a soberania alimentar, mas também a soberania tecnológica e energética dentro de um contexto de resiliência (ALTIERI; TOLEDO, 2011, p. 28). ${ }^{23}$

Assim, há uma forte dimensão política e social no contexto da agroecologia, pois os sistemas agrícolas são resultantes de uma co-evolução entre ecossistemas e comunidades humanas (ALTIERI, 2004; VAN DER PLOEG, 2011). Além dos agroecossistemas serem construídos socialmente, a agroecologia se contrapõe à hegemônica agricultura convencional. Nesse sentido, há uma forte crítica ao sistema agroalimentar industrial por parte dos movimentos sociais camponeses e agroecológicos.

\footnotetext{
23 " "...] la soberanía alimentaria se centra en la autonomía local, los mercados locales, los ciclos locales de producción y consumo, y las redes de agricultor a agricultor que promueven innovaciones e ideas agroecológicas. La agroecología no sólo proporciona los principios para alcanzar la soberanía alimentaria, sino también la soberanía tecnológica y energética dentro de un contexto de resiliencia."
} 
Molina (2009) defende que a agroecologia incorpore a dimensão política, haja vista que as relações de poder, que são políticas, permeiam o conjunto das relações sociais e ambientais.

Os movimentos sociais no meio rural devem entender que o desmantelamento do sistema agroalimentar industrial e a restauração dos sistemas alimentares locais deverá ser acompanhado da construção de alternativas agroecológicas que se adaptem às necessidades dos pequenos produtores e da população não camponesa pobre, algo oposto ao controle corporativo sobre a produção e o consumo (ALTIERI; TOLEDO, 2011, p. 29-30).

A agroecologia critica o poder das corporações transnacionais, que são as maiores responsáveis pela redução da autonomia alimentar em diferentes regiões do mundo, através do controle de grande parte das sementes, insumos, maquinários e outros produtos do setor agroalimentar (SICARD, 2009).

Uma das bandeiras de luta política em favor da agroecologia diz respeito à necessidade de mudanças na forma de se manejar os agroecossistemas e ao fortalecimento da autonomia dos agricultores, através do avanço das experiências empíricas, bem como da institucionalização de políticas públicas por parte do Estado. Nesse sentido, para o acesso aos instrumentos (programas, incentivos, crédito, assistência técnica) que estão nas mãos do Estado, a participação política dos agricultores e de outros sujeitos adeptos à agroecologia é indispensável (GABOARDI; CANDIOTTO, 2015, p. 6753).

A agroecologia tem sido justificada pelo fato de poder contribuir para a redução dos problemas oriundos das mudanças climáticas - devido à resiliência dos agroecossistemas -; no combate à desnutrição; no fortalecimento de sistemas alimentares construídos localmente e na consequente viabilidade econômica de áreas rurais, através de cadeias curtas de comercialização; e na produção alimentar segura e justa. A agroecologia defende a produção alimentar na escala local, agricultores familiares, comunidades rurais, a soberania alimentar, os conhecimentos locais, a justiça social, as identidades culturais locais e os direitos indígenas às sementes e raças de animais (HLPE, 2016). 
A agroecologia pressupõe um processo de construção social, sendo um conceito dinâmico, definido coletivamente em uma comunidade ou entre comunidades, através de intercâmbios horizontais e da aprendizagem mútua entre agricultores produtores de alimentos (FAO, s/d). Nesse sentido, podem existir diferentes definições e interpretações sobre a agroecologia por parte de grupos de agricultores.

O documento mais recente e representativo sobre agroecologia produzido pelos movimentos camponeses é a Declaração de Nyéléni (2015). Nele, a agroecologia não é entendida somente como uma ciência ou um conjunto de tecnologias inovadoras, mas, principalmente, como algo que pode contribuir para um processo de transformação da sociedade, pois envolve necessariamente a soberania alimentar e territorial, a autonomia dos camponeses, e mudanças nas relações de poder. Segundo a Declaração, a Agroecologia é um movimento e uma prática liderada pelas pessoas, que precisa ser apoiado, e não conduzido, pela ciência e pela política. Nessa perspectiva, a dimensão da agroecologia enquanto um movimento social de transformação da própria relação entre sociedade e natureza, é enfatizada.

No Marco Referencial sobre Agroecologia da Empresa Brasileira de Pesquisa Agropecuária (EMBRAPA), de 2006, que se caracteriza como um documento técnico, a agroecologia é destacada enquanto ciência e movimento.

[...] podemos falar em Agroecologia tanto como enfoque científico quanto como movimento social. Como ciência, ela vem sendo sistematizada desde a década de 1980, dotando os então denominados movimentos de agricultura alternativa de maior consistência conceitual e metodológica. Como movimento social, tem permitido trazer para o debate público a questão do poder da ciência sobre o desenvolvimento da sociedade, realçando o caráter eminentemente político que há por trás das opções entre diferentes modelos tecnológicos empregados na agricultura (EMBRAPA, 2006, p. 15-6).

Portanto, mesmo em uma instituição de caráter mais técnico, a agroecologia é entendida como algo inovador, ao questionar relações de poder que permeiam a produção de alimentos, mas também ao propor ações que objetivam concretizar um processo de 
transformação social, por meio da ação política de agricultores, pesquisadores, movimentos sociais e outros sujeitos.

Apesar de instituições com caráter mais técnico, como a EMBRAPA, no Brasil, e a FAO, na escala global, incorporarem aspectos que denotam a multidimensionalidade da agroecologia em documentos oficiais e sua importância enquanto movimento de transformação social, é preciso analisar de forma mais aprofundada, as ações efetivas destas instituições no tocante ao fortalecimento e expansão da agroecologia, para que possam ser identificadas possíveis contradições. É comum que os discursos estejam permeados por boas intenções, porém, somente o conhecimento e avaliação das ações de instituições deste tipo, que historicamente têm apoiado o agronegócio, podem desvendar as intencionalidades que estão por trás de determinadas retóricas.

A partir do que foi apresentado até aqui, é perceptível que a agroecologia se apresenta como algo multidimensional e multidisciplinar. Os dois próximos itens, ampliam esse debate.

\section{A multidimensionalidade da agroecologia}

Se partirmos do pressuposto de que a agroecologia tem como elemento central a produção de alimentos, sua multidimensionalidade é algo intrínseco, pois, em primeiro lugar, trata-se de uma relação que os seres humanos e as sociedades estabelecem com o ambiente e o espaço geográfico. Essa relação implica em coexistências entre o mundo natural - incluindo os seres humanos como mais uma espécie biológica - e os valores culturais de diferentes etnias; entre as técnicas desenvolvidas no decorrer da história e sua aplicação e importância econômica; entre a ocupação e transformação do espaço geográfico e as relações de poder que necessariamente condicionam este processo.

[...] quando se fala de Agroecologia, está se tratando de uma orientação cujas contribuições vão muito além de aspectos meramente tecnológicos 
ou agronômicos da produção, incorporando dimensões mais amplas e complexas, que incluem tanto variáveis econômicas, sociais e ambientais, como variáveis culturais, políticas e éticas da sustentabilidade (CAPORAL; COSTABEBER, 2004, p. 13).

Ao ressaltar a multidimensionalidade da agroecologia no plano teórico e empírico, procura-se identificar diferentes dimensões, que apesar de serem coexistentes e interdependentes, serão aqui, rapidamente apresentadas.

\subsection{Dimensão espacial}

A agroecologia implica formas de se ocupar e produzir alimentos e outros bens de consumo, em determinado recorte espacial. De forma geral, a principal escala espacial da agroecologia está no agroecossistema, que é considerado a área onde ocorre o manejo agroecológico, caracterizado pelo cultivo de espécies com finalidades agrícolas. Um agroecossistema, pode ser manejado por uma família de agricultores, por um único agricultor ou por agricultores. Esta área, pode possuir elementos naturais, cultivos agrícolas e criações de animais, com configurações variadas (lavouras, pastos, canteiros, agroflorestas, manejos florestais, sistemas silvopastoris ou agrosilvopastoris, entre outros).

Ao ser manejada por determinado indivíduo, família ou pequeno grupo de agricultores trabalhando em parcerias, um agroecossistema está inserido, política e administrativamente, em um estabelecimento agropecuário (IBGE, 2017), ou, mais especificamente, em um Núcleo de Vida e Gestão Familiar (NVGF) ${ }^{24}$.

Apesar da materialização da agroecologia se dar, majoritariamente, nessa escala nanoterritorial, que é o Núcleo de Vida e Gestão Familiar (NVGF) e seu(s) agroecossistema(s), outras escalas espaciais influenciam as ações em torno da agroecologia. Entre elas, destacam-se a escala microlocal, por meio da organização de agricultores em suas comunidades, em associações e outras instituições políticas e sociais; a escala municipal,

\footnotetext{
${ }^{24} \mathrm{O}$ aprofundamento deste debate será feito no item 7.
} 
através da assistência técnica e extensão rural (no caso de municípios onde existam profissionais capacitados para auxiliar agricultores em sistemas de produção orgânicos) e de possíveis políticas públicas ${ }^{25}$ e incentivos na área da agroecologia; a escala dos estados da Federação (no caso do Brasil), com instituições de apoio, órgãos colegiados (Comissões estaduais de produção orgânica, Conselhos etc.), políticas públicas e incentivos em nível estadual; a escala nacional (país), através de instituições, órgãos colegiados, políticas públicas e incentivos ${ }^{26}$; e a escala internacional, com diversas configurações possíveis e instituições representativas ${ }^{27}$.

\subsection{Dimensão alimentar}

A agroecologia implica necessariamente na produção de alimentos, valorizando saberes tradicionais, as potencialidades de ecossistemas e agrossistemas, a diversificação produtiva e, sobretudo a soberania alimentar. Os alimentos agroecológicos são produzidos de forma distinta dos alimentos característicos do sistema alimentar hegemônico, de modo que um dos princípios da agroecologia está na produção de alimentos sem o uso de agrotóxicos, fertilizantes químicos sintéticos e organismos geneticamente modificados.

\footnotetext{
${ }^{25}$ Entende-se que as políticas públicas englobam normas e ações variadas por parte de organismos governamentais.

${ }^{26}$ No Brasil, foi criada, através do Decreto $n^{\circ}$. 7.794/2012, a Câmara Interministerial de Agroecologia e Produção Orgânica (CIAPO), que é o principal órgão do governo federal responsável por elaborar e executar os Planos Nacionais de Agroecologia e Produção Orgânica (PLANAPO), oriundos da Política Nacional de Agroecologia e Produção Orgânica (PNAPO). O principal órgão colegiado em nível nacional é a Comissão Nacional de Agroecologia e Produção Orgânica (CNAPO), com composição paritária de instituições governamentais e da sociedade civil. No âmbito executivo, o Ministério da Agricultura, Pecuária e Abastecimento (MAPA) é o órgão federal responsável pela implantação da maior parte das ações na área da produção orgânica e da agroecologia. No entanto, por meio do Decreto $n^{\circ} .9 .784 / 2019$, a criação da CIAPO e da CNAPO, foram revogadas. Outras informações podem ser obtidas no portal <www.agroecologia.gov.br $>$.

27 Como exemplos, tem-se o Movimento Agroecológico da América Latina e Caribe (MAELA); a Via Campesina; a Federação Internacional dos Movimentos de Agricultura Orgânica (IFOAM); e a Organização das Nações Unidas para Agricultura e Alimentação (FAO).
} 
“[...] a crise social, ambiental e econômica que enfrentamos exige uma mudança profunda na forma como os nossos sistemas alimentares estão organizados" (CIDSE, 2018, p. 3).

O debate sobre a soberania alimentar está intimamente associado à luta por terra, por recursos naturais e pelos territórios de produção e de vida dos camponeses de todo o planeta. Assim, acreditamos que, soberania alimentar, só existe se houver soberania territorial.

Tal debate, tem colocado em xeque o discurso oficial de organismos internacionais como a FAO, a respeito do conceito de segurança alimentar. Segundo Stédile e Carvalho (2010), soberania alimentar é algo muito mais complexo, que engloba a segurança alimentar, mas que questiona a distribuição das terras e sua apropriação pelas grandes corporações do sistema alimentar global.

"Soberania alimentar é o enquadramento político que aborda as causas dos problemas da fome e da pobreza" [...]. Ela "engloba não apenas o controle da produção e dos mercados, mas também o acesso das pessoas e o controle sobre a terra, a água e os recursos genéticos", os quais permitem produzir alimentos (CIDSE, 2018, p. 4).

Rosset e Altieri (2018), apontam que a Via Campesina vem debatendo e lutando pela soberania alimentar, de modo que a agroecologia está ligada a este debate. Para esses autores, os sistemas alimentares diversificados são fundamentais para fortalecer a soberania alimentar dos camponeses. Os movimentos camponeses, sobretudo a Via Campesina,

[...] defendem o conceito de agroecologia como um pilar da soberania alimentar, que busca a autonomia local, os mercados locais e a ação comunitária em prol do acesso e controle da terra, da água, da agrobiodiversidade etc., elementos de vital importância para que as comunidades possam produzir alimentos localmente (p. 88$)^{28}$.

\footnotetext{
${ }^{28}$ [...] defienden el concepto de agroecología como un pilar de la soberanía alimentaria, que busca la autonomía local, los mercados locales y la acción comunitaria en pro del acceso y el control de la tierra, el agua, la agrobiodiversidad, etc., elementos de vital importancia para que las comunidades puedan producir alimentos localmente.
} 
A ONG CIDSE também ressalta a interdependência entre agroecologia e soberania alimentar, ao entender que a agroecologia é "um dos elementos principais para alcançar a soberania alimentar e a justiça ambiental" (CIDSE, 2018, p. 3 ).

\subsection{Dimensão econômico-produtiva}

Muito se fala na necessidade de a agroecologia ser economicamente sustentável, porém, é preciso questionar e relativizar essa afirmativa. O que é algo economicamente sustentável? No âmbito do Modo de Produção Capitalista, o predomínio da dimensão econômica não tem sido um dos principais elementos de deterioração ambiental e de geração de desigualdades sociais? Se ser economicamente sustentável implica a manutenção da ênfase no lucro, na extração de mais-valia e na concentração da riqueza, provavelmente não seja interessante e viável manter essa lógica. Portanto, entende-se que a dimensão econômica, apesar de ser relevante do ponto de vista da geração de renda e oportunidades de acesso a bens e serviços para os camponeses e suas famílias, não deve ser a prioridade no debate sobre agroecologia. Certamente, é preciso que a agroecologia promova uma renda que permita melhorar as condições de sobrevivência e a qualidade de vida das famílias agricultoras, porém, na agroecologia, a centralidade e hegemonia da dimensão econômica tem sido e devem ser questionadas. Como há um tênue limiar entre o aumento da renda e a subordinação à lógica do capital, as consequências e implicações dos ganhos econômicos, precisam ser levadas em consideração constantemente.

Ao discutir a necessidade de uma racionalidade ambiental, Leff (1994) já evidenciava como somos influenciados por uma racionalidade que é eminentemente econômica. Essa concepção de que a economia é algo superior a outras dimensões acaba sendo determinante para a manutenção do discurso de que é preciso manter a economia funcionando, ou seja, que a economia deve ser sustentada. Assim, quando se fala em sustenta- 
bilidade econômica, a própria ONU, que é responsável pela adoção do conceito de desenvolvimento sustentável e de sustentabilidade, não questiona a lógica de acumulação capitalista.

Giraldo (2018), estabelece uma forte crítica à economia política do extrativismo e evidencia que a economia passa a ser vista como uma instituição autônoma que organiza e rege toda a organização social, “[...] mediante uma produção de conhecimento que coisifica a dimensão humana e ecossistêmica, através da mercantilização do trabalho e da Mãe Terra" (p. 47) 29 . Essa racionalidade acaba influenciando a percepção das pessoas sobre o mundo, bem como a própria ciência.

[... ] a racionalidade econômica invadiu não apenas as disciplinas científicas, com sua terminologia e sua maneira particular de conceber o habitar dos seres humanos, mas, sobretudo, penetrou profundamente nos pressupostos culturais que fundamentam a forma de nos comportarmos e de percebermos a nós mesmos (GIRALDO, 2018, p. 48) ${ }^{30}$.

Consequentemente, “[...] sistemas tradicionais de agricultura, que se caracterizavam pela diversidade de cultivos adaptados a lugares concretos e ecossistemas mega diversos - como no trópico latino-americano -, foram aniquilados e substituídos por mo-

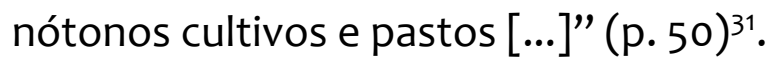

É certo que a dimensão econômica da agroecologia está ligada aos bens produzidos, em termos de quantidade de bens (diversidade) e do montante produzido de cada bem. Conforme defendido por diversos pesquisadores, a diversificação produtiva é um princípio ecológico da agroecologia, fundamental para se fortalecer algum tipo de equilíbrio agroecossistêmico, a soberania alimentar e, de forma secundária, a renda das famílias camponesas. Portanto, a dimensão econômico-produtiva da agroecologia deve estar

\footnotetext{
29 [...] "mediante una producción de conocimiento que cosifica la dimensión humana y ecosistémica a través de la mercantilización del trabajo y de la Madre Tierra".

${ }^{30}[. .$.$] la racionalidad económica invadió no solo a las demás disciplinas científicas con su terminología y su particular$ manera de concebir el habitar de los seres humanos, sino, ante todo, penetró con profundo calado en los supuestos culturales que fundamentan la forma de comportarnos y de percibirnos a nosotros mismos.

31 “" [...] sistemas tradicionales de agricultura que se caracterizaban por la diversidad de cultivos adaptados a lugares concretos, y ecosistemas megadiversos - como en el trópico latinoamericano -, fueron aniquilados y remplazados por monótonos cultivos y pastizales [...]".
} 
associada às dimensões alimentar e ecológica. Caso contrário, o alerta feito por Giraldo e Rosset (2016 e 2017), bem como por Rosset e Altieri (2018) sobre a tendência de cooptação da agroecologia pelo capital, se concretizará rapidamente.

A Declaração de Nyéléni (2015) ressalta a importância de novas relações econômicas para se avançar em termos da construção de uma autonomia através da agroecologia.

[...] autonomia da agroecologia desloca o controle dos mercados globais e gera auto governança das comunidades. Significa que podemos minimizar o uso de insumos comprados que vêm de fora (importados). A Agroecologia requer a reconfiguração dos mercados, para que estes sejam baseados nos princípios da economia solidária e justa, e na ética da produção e do consumo responsáveis. Ela promove sistemas de distribuição curtos, diretos e justos. Ela significa uma relação transparente entre produtoras/es e consumidoras/es e é baseada na solidariedade nos riscos e benefícios compartilhados. (FÓRUM INTERNACIONAL DE AGROECOLOGIA, 2015, p. 5)

\subsection{Dimensão ecológica}

A dimensão ecológica é um dos grandes pilares da agroecologia, sendo também um dos principais diferenciais em relação a agricultura convencional ou ao agronegócio, que são importantes ícones do capitalismo. Os princípios ecológicos são, historicamente, evidenciados na perspectiva agroecológica.

$\mathrm{Na}$ agroecologia, os ciclos naturais e a dinâmica dos ecossistemas e agroecossistemas são elementos que devem fundamentar as práticas agroecológicas. Assim, quando se fala em agroecologia, os processos naturais são decisivos na orientação das espécies a serem cultivadas, considerando interações entre os elementos bióticos e abióticos.

A dimensão ecológica e ambiental da agroecologia se expressa nas condições naturais dos ecossistemas (características climáticas, pedológicas, geomorfológicas, biogeográficas, hídricas e suas interações), que podem ser extremamente úteis para a orienta- 
ção das práticas agroecológicas, mas também nas possibilidades de se potencializar determinadas funções produtivas dos ecossistemas, através de práticas agrícolas, que sejam bem adaptadas às características ecológicas naturais. Desta forma, a natureza pode ser fonte de recursos para as práticas agroecológicas mas, também, as práticas podem contribuir para a manutenção ou o reestabelecimento de relações ecológicas positivas, como a nutrição orgânica de solos, a conservação de corpos hídricos (rios, nascentes, lagos, lençóis freáticos), a regeneração e reprodução de habitats e, consequentemente de organismos vivos, entre outras.

Altieri (1995) já destacava a dimensão ecológica da agroecologia, ao propor os seguintes princípios (ou objetivos) agroecológicos:

1. Ampliar a reciclagem de biomassa, otimizando, com o tempo, a decomposição da matéria orgânica e a ciclagem de nutrientes;

2. Fortalecer o "sistema imunológico" dos sistemas agrícolas, mediante o aumento da biodiversidade funcional - inimigos naturais, antagonistas etc., criando habitats apropriados;

3. Proporcionar, ao solo, condições mais favoráveis para o crescimento vegetal, especialmente através do manejo da matéria orgânica e aumento da atividade biológica dos solos;

4. Minimizar as perdas de energia, água e recursos genéticos, através da conservação e regeneração dos recursos hídricos, edáficos e da agrobiodiversidade;

5. Diversificar as espécies e os recursos genéticos do agroecossistema, no tempo e no espaço, na escala das lavouras e das paisagens;

6. Aumentar as interações biológicas e sinergias benéficas entre os componentes da agrobiodiversidade, fomentando os processos e serviços ecológicos mais relevantes (grifos nossos). 
Em uma de suas obras clássica, Gliessman (2001) apresenta o papel de fatores abióticos, como a luz, a temperatura, a umidade e a chuva, o vento e o solo, no desenvolvimento das plantas e outros organismos vivos, além de discutir diversas interações ecológicas que ocorrem nos agroecossistemas.

Ao associar a importância dos conhecimentos sobre a natureza para se construir o que chama de saber agroecológico, Enrique Leff (2002), dá um passo além da dimensão produtiva na valorização dos processos ecológicos. "O saber agroecológico contribui para a construção de um novo paradigma produtivo ao mostrar a possibilidade de produzir com a natureza, de gerar um modo de produção fundado no potencial ecológico-tecnológico da natureza e da cultura" (p. 44). Essa valorização da natureza pode ser um elemento chave na construção de um novo paradigma produtivo e de um processo de transformação social. Toledo (2016), também fala da agroecologia como um novo paradigma e aponta para sua relevância em um processo de revolução epistemológica.

\subsection{Dimensão técnica}

A dimensão técnica da agroecologia envolve, sobretudo, os conhecimentos e as técnicas utilizados para o manejo dos agroecossistemas e para a produção de alimentos e outros bens. Assim, o manejo do solo e os insumos orgânicos utilizados para sua fertilização, como a matéria orgânica oriunda de podas e roçadas; as matérias-primas para a produção, como sementes, mudas e raças de animais; os insumos utilizados, sendo eles obtidos preferencialmente nos próprios agroecossistemas; as ferramentas e máquinas ligadas à produção e ao processamento dos alimentos; entre outras técnicas, fazem parte do arcabouço técnico da agroecologia.

Os conhecimentos tradicionais, inclusive milenares, são reconhecidos e valorizados no âmbito da agroecologia. Da mesma forma, o desenvolvimento e criação de novos 
equipamentos, adaptados às características da agricultura camponesa e aos ecossistemas onde se materializam as práticas agroecológicas, também são de suma importância, e compõem a dimensão técnica.

Essa junção entre conhecimentos tradicionais e conhecimentos científicos avançados e inovadores é importante e necessária para o fortalecimento da agroecologia. Caporal e Costabeber (2006) ressaltam a agroecologia é uma ciência interdisciplinar, que considera os conhecimentos empíricos locais dos agricultores como ponto de partida para o diálogo com conhecimentos científicos diversos.

Para Altieri (2000), a Agroecologia se pauta nos seguintes elementos técnicos, que por sua vez, devem ser orientados a partir de princípios de conservação e manejo ecológicos:

- Conservação e regeneração dos recursos naturais, como o solo, a água, recursos genéticos, fauna e flora;

- Manejo dos recursos produtivos, através da diversificação, reciclagem dos nutrientes e da matéria orgânica e da regulação biótica;

- Implementação de elementos técnicos, com base na definição de técnicas ecológicas, escala de trabalho, integração dos elementos do sistema em foco e adequação à racionalidade dos agricultores.

"As práticas produtivas da agroecologia incluem as culturas intercaladas, a pesca tradicional e a criação de animais em sistemas móveis - integrando lavouras árvores criações e pesca -, o uso de esterco, compostagem, sementes e raças de animais locais etc." (FÓRUM INTERNACIONAL DE AGROECOLOGIA, 2015, p. 4)

Todavia, cabe ressaltar, que no contexto das inovações científicas, também há uma priorização de técnicas e tecnologias voltadas à agricultura capitalista, caracterizada pela produção em larga escala, monoculturas, manipulação genética, uso de insumos químicos sintéticos etc. O perfil profissional de professores e pesquisadores, assim como as disciplinas e os conteúdos dos cursos de ciências agrárias, geralmente, são direcionados 
ao agronegócio. Nesse sentido, as universidades e as instituições de desenvolvimento tecnológico vinculadas aos setores agrícola e pecuário, pouco se interessaram por criar, desenvolver e implementar técnicas adequadas aos princípios da agroecologia. Isso é um elemento importante para se entender por que quase não existem muitas inovações técnicas direcionadas para a agroecologia.

\subsection{Dimensão político-organizativa}

A dimensão política da agroecologia tem sido debatida no âmbito da Ecologia Política, Geografia, Sociologia e outras áreas do conhecimento. Essa dimensão também tem se tornado uma bandeira de luta, sendo defendida com veemência pelos movimentos sociais camponeses, como a Via Campesina e outras organizações.

A vertente política da agroecologia dá uma expressão prática à soberania alimentar, colocando os pequenos produtores de alimentos no centro dos processos e decisões políticas que os afetam. Procura enfrentar múltiplos desafios, desde a segurança do acesso aos recursos produtivos (terra, água, sementes) à segurança alimentar e nutricional [...] (CIDSE, 2018, p. 9).

Segundo o documento do Fórum Internacional de Agroecologia (2015), organizado por movimentos sociais, é preciso reafirmar a dimensão política da agroecologia.

Agroecologia é política - ela exige que enfrentemos, desafiemos e transformemos as estruturas de poder da sociedade. Temos que colocar o controle das sementes, da biodiversidade, da terra e dos territórios, das águas, do conhecimento, da cultura e dos bens comuns nas mãos daquelas/es que alimentam o mundo. (p. 5)

Em seu livro intitulado Ecología Política de la Agricultura: agroecologia e posdesarrollo, Giraldo (2018) discorre sobre o processo de hegemonização da agricultura capitalista agroextrativista, através da intensificação da acumulação por despossessão, discutida por David Harvey, bem como da utilização de um discurso que é amplamente apoiado pela própria ciência. 
Para Rosset e Altieri (2018, p. 187), há uma disputa entre duas concepções de agroecologia.

Vivenciamos uma disputa entre duas maneiras radicalmente distintas de se conceber a agroecologia: uma técnica e tecnocêntrica, cientificista e institucional, e outra "popular, "dos povos", que é profundamente política e que preconiza a justiça distributiva e uma profunda transformação do sistema alimentar. ${ }^{32}$

Apesar de Rosset e Altieri (2018) parecerem afirmar que, no dualismo entre uma visão institucional de agroecologia e uma visão popular, somente a visão popular é profundamente política, entendemos que, mesmo no contexto da visão tecnocêntrica e institucional da agroecologia, existe um forte viés político, vinculado a utilizar um discurso ambientalmente e socialmente correto, para justificar a manutenção da mesma lógica de acumulação que tem predominado no capitalismo. Portanto, a dimensão política da agroecologia se dá por todos aqueles que utilizam este termo, da mesma forma como ocorre em relação ao termo sustentabilidade. Mesmo concordando que os termos agroecologia e sustentabilidade têm sido despolitizados, entendemos que a utilização de uma retórica contrária a politização destes termos, por si só, é uma forma de se politizar o debate. Assim, aqueles que buscam despolitizar a agroecologia possuem uma intencionalidade vinculada ao enfraquecimento dos movimentos camponeses que colocam a agroecologia como bandeira de luta política.

No cotidiano, o discurso contra a ideologização tem servido para culpabilizar qualquer movimento de contestação do status quo, bem como para imprimir uma ideologia conservadora de forma oculta.

No contexto da dimensão política da agroecologia, os processos de organização social também são fundamentais para que seja possível imprimir transformações sociais relevantes.

\footnotetext{
32 "Nos enfrentamos a una disputa entre dos maneras radicalmente distintas de concebir la agroecología: una técnica y tecnocéntrica, cientificista e institucional, y la otra "popular, "de los pueblos", que es profundamente política y que preconiza la justicia distributiva y una profunda transformación del sistema alimentario."
} 
As possibilidades que abre a Agroecologia para converter os recursos agrícolas e florestais em bases para o desenvolvimento e bem-estar das comunidades rurais aparece, também, como um meio para a proteção efetiva da natureza, da biodiversidade e do equilíbrio ecológico do planeta. A consolidação destes processos dependerá do fortalecimento da capacidade organizativa das próprias comunidades, para desenvolver alternativas produtivas que permitam melhorar suas condições de vida e aproveitar seus recursos de forma sustentável (LEFF, 2002, p. 46). (grifo nosso).

Apesar de também adotar o conceito de sustentabilidade, Leff se mostra um pouco mais crítico em relação à maioria dos autores que utilizam este conceito, pelo fato de entender que é fundamental uma superação da racionalidade econômica por uma racionalidade ambiental. Ao contrário daqueles autores que não questionam os limites da ideia de um desenvolvimento sustentável no contexto do Modo de Produção Capitalista, Leff (1994, 2002), associa a sustentabilidade a um amplo processo de transformação da própria relação entre sociedade e natureza.

\subsection{Dimensão sociocultural}

Conforme já salientado no item sobre dimensão técnica, a dimensão sociocultural da agroeocologia é permeada pela valorização de conhecimentos tradicionais. Todavia, não é porque a agroecologia valoriza tais tipos de conhecimentos, que ela é um retorno ao passado ou algo atrasado e arcaico, como muitos de seus críticos ponderam.

As pesquisas e a geração de novos conhecimentos são fundamentais para o avanço da agroecologia, de modo que o diálogo de saberes pode ser amplamente viabilizado. "A Agroecologia, tem base na relação sinérgica entre a evolução do conhecimento científico e do saber popular e a sua necessária integração" (EMBRAPA, 2006, p. 26).

A partir da década de 1980, a Agroecologia incorporou a importância de unir o saber popular para realizar o manejo sobre o ambiente e sobre os recursos naturais nos processos produtivos agrícolas ou extrativistas. Dessa forma, o saber acumulado pelas comunidades tradicionais ao longo dos anos passou a ser considerado [...] (GABOARDI; CANDIOTTO, 2015, p. 6749). 
Na Declaração de Nyéléni, documento do Fórum Internacional de Agroecologia (2015) e em outros documentos e obras, uma marca da agroecologia é o fato dela ser praticada por camponeses. Mesmo antes de ser uma ciência, a agroecologia é prática, ou seja, foi constituída por diversas práticas socioculturais de camponeses de todo o mundo. Portanto, a agroecologia é, também, o reconhecimento da autodeterminação e autonomia dos povos, sejam homens, mulheres ou jovens.

Ao colocar os produtores de alimentos no centro dos sistemas alimentares (trocas de práticas entre pares, promoção das competências dos produtores de alimentos etc.), aumentando a autonomia e revitalizando as áreas rurais, a agroecologia contribui para dar um novo valor às identidades camponesas e ao fortalecimento da confiança dos camponeses e envolvimento no sistema alimentar local (CIDSE, 2018, p. 7).

A afirmação sociocultural da agroecologia como algo específico dos camponeses é também um posicionamento político contra sua cooptação institucional e/ou científica. Tal afirmação tem sido pautada, sobretudo, por movimentos sociais do campo, bem como por pesquisadores, ativistas e agricultores dos países colonizados, com destaque para a América Latina, África e Caribe.

No contexto latino-americano, a agroecologia tem sido associada a um processo de transformação social e a uma perspectiva decolonial. O giro decolonial, a luta pela autonomia camponesa, o bem-viver, entre outras perspectivas analíticas alternativas têm sido muito úteis para dar um corpo teórico e epistemológico para a agroecologia.

Altieri e Toledo (2011), elencaram as seguintes características epistemológicas da agroecologia na América Latina:

- Integra processos naturais e sociais, interessando a áreas (ou enfoques) híbridos (ou multidisciplinares), como a ecologia política, econômica ecológica e etnoecologia;

- Adota um enfoque holístico e, por isso, é considerada multidisciplinar, tendo no agroecossistema, um conceito socioecológico;

- A agroecologia não é neutra, de modo que assume a crítica ao paradigma agrícola convencional; 
- Reconhece e valoriza os saberes e tradições locais;

- Possui uma visão de longo prazo;

- É uma ciência dotada de uma ética social e ecológica.

Conforme já colocado, há uma coexistência entre as sete dimensões discutidas acima, de modo que elas se confundem no plano empírico. Assim, é difícil apreender todos os elementos de todas elas juntas ou de cada uma de forma completa e fragmentada. São exercícios de análise que devem ser aperfeiçoados, com base na análise de experiências empíricas e no constante processo dialógico entre teoria e práxis.

\section{O caráter multidisciplinar da agroecologia}

O debate sobre o caráter multi, inter ou transdisciplinar da agroecologia tem sido intenso, de modo que, geralmente, se trabalha com a ideia de que ela envolve ou pode envolver diversas áreas do conhecimento e disciplinas científicas.

Apesar de a agroecologia ser considerada uma disciplina, ela também é vista como um tema ou enfoque, que permite a integração entre conhecimentos científicos variados, assim como entre o conhecimento científico e outros saberes, sobretudo os saberes populares e vernaculares.

A Agroecologia convoca a um diálogo de saberes e intercâmbio de experiências; a uma hibridação de ciências e técnicas, para potencializar as capacidades dos agricultores; a uma interdisciplinaridade, para articular os conhecimentos ecológicos e antropológicos, econômicos e tecnológicos, que confluem na dinâmica dos agroecossistemas (LEFF, 2002, p. 42).

Wezel et al. (2009), ressaltam a natureza transdisciplinar do enfoque agroecológico, sobretudo através da possibilidade de diálogo entre ciências naturais e ciências sociais. "O pensamento agroecológico, inicialmente, enfocou a produção agrícola. Porém, nas últimas décadas, novas dimensões tornaram-se relevantes, como a ambiental, social, 
econômica, ética e o desenvolvimento" (WEZEL et al., 2009, p. 503)33. No artigo de Wezel et al. (2009), são mencionados outros autores que percebem a agroecologia como uma interdisciplina ou uma transdisciplina. Contudo, há um grande desafio em se construir metodologias de análise integrada entre as diversas áreas do conhecimento envolvidas com a agroecologia, de modo que as ferramentas metodológicas irão depender da escala e dos objetivos das abordagens.

Como o diálogo com saberes tradicionais é uma marca na agroecologia, as metodologias participativas também são exaltadas, para que a linguagem entre os sujeitos seja clara e objetiva. Caporal, Costabeber e Paulus (2006), relacionam diversos tipos de conhecimentos vinculados a agroecologia (p. 8).

Segundo o Marco referencial da EMBRAPA (2006), a agroecologia é uma ciência emergente, orientada por uma nova base epistemológica e metodológica. Ela "é considerada como campo de conhecimento transdisciplinar, que recebe as influências das ciências sociais, agrárias e naturais, em especial da Ecologia Aplicada" (p. 25).

Ao discutir a multidimensionalidade da agroecologia, seu caráter multidisciplinar também foi, de certa forma, evidenciado.

\section{A multiescalaridade da agroecologia}

Pelo fato de ser um fenômeno que é praticado em agroecossistemas e estabelecimentos agropecuários ou em Núcleos de Vida e Gestão Familiar (escala nanoterritorial), perpassando comunidades rurais, municípios, estados, países - entre outras escalas espaciais - e, que tem sido incorporado no debate global sobre o sistema alimentar global e sobre o futuro da agricultura e da alimentação, a agroecologia também possui um caráter multiescalar.

\footnotetext{
33 "Though agroecology initially dealt primarily with crop production and protection aspects, in recent decades new dimensions such as environmental, social, economic, ethical and development issues are becoming relevant".
} 
Ao entender que as escalas geográficas dos fenômenos (SOUZA, 2013) estão interligadas, e que a escala nanoterritorial e microlocal costumam ser priorizadas nos estudos e pesquisas sobre agroecologia, enquanto escalas de análise e de ação (SOUZA, 2013), com destaque para os NVGF, faz-se mister, associar essas escalas a outros níveis escalares, até a escala global, pois existe um debate internacional sobre a agroecologia, seja por parte de instituições oficiais como a FAO, seja por organizações camponesas, como a Via Campesina.

Wezel et al. (2009), destacaram que os pesquisadores da agroecologia foram modificando suas escalas de análise, de modo que, entre as décadas de 1930 e 1970, predominaram pesquisas na escala das lavouras e áreas agrícolas; de 1970 a 2000, ampliaramse as pesquisas para a escala dos agroecossistemas e dos estabelecimentos agropecuários; e, a partir de 2000, a agroecologia passou a ser discutida na escala global, ao se levar em consideração todo o sistema alimentar mundial. Não se trata de uma mudança de escala, mas de um processo de escalonamento da agroecologia, que é salutar e necessário, na visão de Rosset e Altieri (2018), Mier et al. (2018). Este debate sobre a ampliação das escalas de análise, mas sobretudo da escala de ação da agroecologia, tem ganhado força no meio científico, de modo que em agosto de 2019, o periódico Agroecology and Sustainable Food Systems publicou um número especial, denominado Scaling Agroecology.

No plano da escala de ação (SOUZA, 2013), Rosset e Altieri (2018) alertam que o desafio atual se encontra na ascensão da agroecologia para uma escala superior (expansão quantitativa), para que ela seja praticada por mais famílias, em territórios cada vez mais amplos. Este, seria o escalonamento horizontal, porém, também é preciso que a agroecologia tenha um escalonamento vertical, através do debate político sobre sua importância e viabilidade em termos de transformação do sistema alimentar global. 
Entendemos que esse escalonamento seria qualitativo (reconhecimento da complexidade e do potencial de transformação social e ambiental da agroecologia em instituições diversas), mas também quantitativo (expansão da agroecologia em escalas mais amplas, como a dos países e do planeta).

No contexto das práticas agroecológicas, o documento da EMBRAPA (2006), afirma que a agroecologia ganha caráter concreto quando aplicada às realidades locais, de modo que as experiências locais podem validar os princípios, ponderando cada qual e enriquecendo a própria concepção teórica da Agroecologia.

Apesar dessa relevância da priorização da escala local na agroecologia no que diz respeito à expansão quantitativa das práticas agroecológicas, e da recente consideração da escala global (sistema alimentar) na agroecologia, mencionada por Wezel et al. (2009), entende-se que a Geografia pode contribuir, teórica e epistemologicamente, para que os estudos sobre agroecologia possam estabelecer um diálogo multiescalar, da escala nanoterritorial até a global, considerando-se outras escalas intermediárias.

As escalas espaciais, além de serem construções sociais, também são interdependentes, de modo que existe uma política de escalas. Desta forma, o nanoterritorial e o microlocal não se explicam por si só, sem se levar em consideração escalas espaciais mais amplas, até a global ${ }^{34}$.

Mier et al. (2018), acreditam que o escalonamento da agroecologia para um nível global, envolve um árduo trabalho, que deve se dar, nas mais variadas escalas geográficas.

Considerando que as escalas nanoterritorial e microlocal (SOUZA, 2006, 2013) são fundamentais para se identificar e analisar a dimensão espacial da agroecologia em termos de práticas agroecológicas desenvolvidas (escala de ação), buscou-se discutir essas

\footnotetext{
34 Souza (2013, p. 179-216) discute a escala geográfica enquanto uma construção social, a política de escalas, e apresenta uma proposta de tipologia para escalas geográficas, que iria da nanoterritorial à global.
} 
escalas no contexto do rural, relacionando-as a termos geográficos elaborados na ocasião de uma pesquisa sobre agroecologia, como Núcleo de Vida e Gestão Familiar, Território de Gestão e Lugar de Vida ${ }^{35}$.

\subsection{Escala nanoterritorial}

Um nanoterritório é um território pequeno, como a moradia e o local de trabalho ou lazer. Neles, "as relações de poder remetem a interações face a face entre indivíduos, [...] em situação de co-presença." (SOUZA, 2016, p. 317).

Ao extrapolar a ideia de nanoterritórios para o rural, é possível afirmar que a principal unidade espacial de análise é o Núcleo de Vida e Gestão Familiar (NVGF), que corresponderia, relativamente, ao estabelecimento agropecuário, definição oficial utilizada pelo IBGE. Mais do que, simplesmente, um espaço produtivo, característico do conceito de estabelecimento agropecuário, um NVGF incorpora outras dimensões nesse mesmo recorte espacial, como a topofílica (lugar) e as relações sociais entre a família (territorialidades).

O conceito de Núcleo de Vida e Gestão Familiar (NVGF) foi inspirado no conceito de Núcleo Social de Gestão do Agroecossistema (NSGA), definido no Método de análise econômico-ecológica de Agroecossistemas elaborado por Petersen et al. (2017). Enquanto o "agroecossistema é definido como uma unidade social de apropriação e conversão de bens ecológicos em bens econômicos", sua delimitação física é demarcada "por um Núcleo Social de Gestão do Agroecossistema (NSGA). Na agricultura familiar, o NSGA costuma ser a própria família", adicionada de seu território, ou seja, dos limites de seu estabelecimento familiar (PETERSEN et al., 2017, p. 32).

Assim, para Petersen et al. (2017), o agroecossistema é sinônimo de Núcleo Social de Gestão do Agroecossistema (NSGA), bem como de família. No entanto, ao entender

\footnotetext{
${ }^{35}$ A referida pesquisa foi desenvolvida no estágio de pós-doutorado do autor (2018-2019), realizado no Programa de Pós-graduação em Geografia da UFRJ, sob supervisão do prof. Dr. Marcelo Lopes de Souza.
} 
que seria possível decodificar e ampliar a abrangência de um Núcleo Social de Gestão do Agroecossistema (NSGA), propôs-se o conceito de Núcleo de Vida e Gestão Familiar (NVGF), além de outros conceitos correlatos.

Com base em Souza (2013; 2017), entende-se que um Núcleo de Vida e Gestão Familiar (NVGF), diz respeito a um recorte do espaço social, ou a um nanoterritório, envolvendo um substrato espacial material (aspectos da natureza e objetos técnicos), relações sociais e imaginários dos sujeitos (família e outras pessoas) que vivenciam esse NVGF. Nele, uma família é responsável por sua gestão e, geralmente, essa família reside ou vive parte de seu tempo de vida e de trabalho. Por isso, para além de um Núcleo de Gestão, onde ocorrem atividades produtivas e administrativas, trata-se também de um Núcleo de Vida, onde existem e identidades/topofilias (lugar), mas, também, relações de poder (territorialidades). Portanto, um NGVF é um território, sendo assim, mais do que um agroecossistema, pois engloba todas as áreas de propriedade, manejo e vivência de seus membros (família). Entendemos que o NVGF seria a principal unidade espacial para se apreender a agroecologia, na escala nanoterritorial.

Em termos de ocupação social, um NVGF é composto por uma família, correspondente às pessoas que vivem no NVGF e a parentes de $1^{\circ}$ grau (pais e filhos) que não vivem ali, bem como por outros membros, que podem ser pessoas que vivem no NVGF ou que, mesmo não vivendo, tem alguma influência direta em sua gestão ou no trabalho.

O NVGF também é composto por um ou mais Agroecossistemas (AES), Territórios de Gestão (TG) e Lugares de Vida (LV). Nessa perspectiva, o Agroecossistema é empregado para evidenciar a dimensão ambiental (biofísica, ecológica e produtiva) do NVGF. Um NVGF pode ser composto por um ou mais agroecossistemas. No caso de o NVGF ser composto por uma área contínua, ele terá um agroecossistema, que por sua vez, será composto por um ou mais agrossistemas e/ou ecossistemas. Já no caso de o NVGF ser composto por áreas descontínuas, ele terá dois ou mais agroecossistemas, com seus respectivos agrossistemas e/ou ecossistemas. 
No agroecossistema, podem existir ecossistemas (ES), que são áreas preservadas e não manejadas com finalidade produtiva; e agrossistemas (AS), correspondentes a áreas cultivadas e manejadas (áreas agrícolas, pecuárias, silvicultura etc.). Entre ecossistemas e agrossistemas, pode ou não haver algum tipo de interação produtiva, porém, certamente, sempre existirão interações ecológicas entre eles.

Um agroecossistema corresponde a uma área contínua, de propriedade ou gestão de um ou mais membros do NVGF. Ele pode ser equivalente a um Território de Gestão (gestão familiar unificada) ou abrigar mais de um Território de Gestão (quando há separação na gestão de um agroecossistema ${ }^{36}$ ). Caso a família viva em uma área contínua e exerça toda a gestão, residência e trabalho de forma coletiva, o NVGF será também o Território de Gestão e o Lugar de Vida. Caso contrário, um NVGF terá mais de um Território de Gestão e poderá ter mais de um Lugar de Vida.

No Território de Gestão, a gestão é o elemento-chave de caracterização. Ela envolve o poder para as pessoas envolvidas tomarem as decisões sobre o manejo desse território. Essas pessoas, sempre serão responsáveis por algum tipo de decisão/trabalho (no sentido administrativo), mas não necessariamente empregarão sua própria força de trabalho. Assim, no Território de Gestão, pode ou não haver isonomia entre os membros do NVGF.

Já o Lugar de Vida (LV), envolve as residências e outros espaços de atividades coletivas dentro de um NVGF. É o local onde a família convive e desenvolve atividades ligadas ao trabalho, lazer, descanso etc. Cada membro do NVGF poderá ter diferentes lugaridades no Lugar de Vida, porém, apesar de divisões (quartos e outros cômodos), ele se caracteriza como a principal área de vivência coletiva dos membros do NVGF. É um local onde constroem-se sentidos de lugar com base na convivência familiar. Além de um lugar, a residência também é um território. Ali, também existem relações de poder, que influenciam na própria percepção das pessoas sobre seu Lugar de Vida.

\footnotetext{
${ }^{36}$ Essa separação pode se dar quando parcelas de um agroecossistema (agrossistema ou ecossistema específico) é administrado por um ou mais membros da família (não englobando todo o núcleo familiar).
} 
Sabendo que há uma relação próxima entre a escala nanoterritorial com a escala microlocal, entende-se que cabem algumas observações a respeito da última, pelo fato de existirem relações de proximidade física, política, social e ambiental entre NVGFs, agroecossistemas e seu entorno mais próximo.

\subsection{Escala microlocal}

Ao discutir a escala local, que seria a escala superior à escala dos nanoterritórios, Souza (2013) a fragmenta em microlocal, mesolocal e macrolocal. A escala local, "se refere a recortes espaciais que, em graus variáveis, de acordo com seu tamanho, expressam a possibilidade de uma vivência pessoal intensa do espaço, [...] representando uma situação de maior proximidade física entre os cidadãos e a sede do poder estatal" local (p. 201-202).

Souza (2013, p. 203) associa a escala microlocal a "espaços passíveis de serem experienciados intensa e diretamente no quotidiano", como um quarteirão ou um bairro.

Os diversos subníveis da escala microlocal são [...] relevantes do ponto de vista da auto-organização comunitária/associativa dos cidadãos [...]. [...] essa escala microlocal é ou seria decisiva em qualquer tentativa de descentralização decisória fomentada por movimentos sociais e na esteira de lutas populares e processos de transformação social rumo a uma superação da heteronomia [...] (SOUZA, 2013, p. 203-204).

No contexto do rural, uma comunidade, vila, aldeia ou outro tipo de área rural pequena, para além do estabelecimento agropecuário e do NVGF (nanoterritórios), corresponderia a escala microlocal. Assim, a população de uma comunidade rural, grupos de agricultores de uma comunidade ou de comunidades vizinhas, e suas respectivas formas de organização social, fariam parte da escala microlocal. Nessa escala, de grande relevância política, seria possível estabelecer reivindicações diretas da população frente o Estado (município), como ações de apoio à agroecologia. 


\subsection{Outras escalas espaciais}

Apesar da possibilidade de se definir diversas escalas espaciais, pelo fato de as escalas serem definidas através de um processo de construção social, no tocante a agroecologia, outras escalas espaciais além da nanoterritorial e microlocal, podem ser destacadas. Conforme já colocado, a escala microlocal, seria a principal escala para ações e processo de organização de agricultores em suas comunidades, em associações e outras instituições políticas e sociais. Essa organização, seria fundamental para se dialogar com a administração pública municipal, ou seja, na escala do município, que segundo Souza (2013), corresponderia a escala mesolocal. Nessa escala (mesolocal/municipal), a agroecologia pode ser apoiada e promovida através da assistência técnica e extensão rural (no caso de municípios onde existam profissionais capacitados para auxiliar agricultores em sistemas de produção orgânicos, e vontade política para se fortalecer a agroecologia), de ações realizadas por outros setores (infra-estrutura, vias de acesso, transportes, logística, comércio, educação, saúde, entre outros), bem como, de diversos tipos de políticas públicas e incentivos.

Outra escala político-administrativa extremamente relevante no Brasil, diz respeito aos estados da Federação. Os estados, assim como meso e microrregiões oficiais, estariam englobados, segundo Souza (2013), na escala regional. A atuação dos estados, além de direcionar ações em todos os seus municípios, está relacionada a existência de instituições de apoio à agroecologia, órgãos colegiados (Comissões estaduais de produção orgânica, Conselhos etc.), políticas públicas e incentivos em nível estadual.

Também se destacam a escala nacional (país), através de instituições, órgãos colegiados, políticas públicas e incentivos; e a escala internacional, com diversas configurações possíveis e instituições representativas. ${ }^{37}$

\footnotetext{
37 Como exemplos, tem-se o Movimento Agroecológico da América Latina e Caribe (MAELA); a Via Campesina; a Federação Internacional dos Movimentos de Agricultura Orgânica (IFOAM); e a Organização das Nações Unidas para Agricultura e Alimentação (FAO).
} 
Nesse sentido, existem diversas relações de interdependência entre as escalas mencionadas acima.

\section{O potencial de transformação social da agroecologia}

O potencial transformador da agroecologia, pode estar em novas formas de percepção e de interação da sociedade com a natureza e nos valores éticos que fundamentam essa relação; no questionamento de limites e problemas da ciência pautada em valores ocidentais (como modernidade, colonialidade, produtivismo e desenvolvimento); e, nas lutas por justiça ambiental/social e contra a degradação ambiental.

Vários pesquisadores ressaltam essa possível contribuição da agroecologia no processo de transformação social. Essa perspectiva, está intimamente associada ao caráter político da agroecologia. Entre eles, destacam-se Rosset e Altieri (2018), Giraldo (2018), Giraldo e Rosset (2016 e 2017), Toledo (2016), Gaboardi e Candiotto (2015), Altieri e Toledo (2011), González de Molina (2011) e Leff (2002).

Os movimentos sociais associados ao desenvolvimento do novo paradigma agroecológico e a práticas produtivas no meio rural não são senão parte de um movimento mais amplo e complexo orientado em defesa da transformação do Estado e da ordem econômica dominante. O movimento para um desenvolvimento sustentável é parte de novas lutas pela democracia direta e participativa e pela autonomia dos povos indígenas e camponeses, abrindo perspectivas para uma nova ordem econômica e política mundial (LEFF, 2002, p. 47).

Segundo documento da Via Campesina de 2014, citado por Rosset e Altieri (2018, p. 25-26),

A Agroecologia é a resposta à pergunta sobre como transformar e restabelecer nossa realidade material no contexto de um sistema alimentar e de um mundo rural que foram devastados pela produção industrial de alimentos e as chamadas Revoluções Verde e Azul. Consideramos a Agroe- 
cologia como um modo fundamental de resistência a um sistema econômico que prioriza o benefício econômico diante da vida. [...] As soluções reais para as crises do clima, da desnutrição etc. não virão com o modelo industrial. Precisamos transformá-lo e construir nossos próprios sistemas alimentares locais, que estabeleçam novos vínculos campo-cidade, com base em uma produção de alimentos verdadeiramente agroecológica, feita pelas camponesas e camponeses, pescadores artesanais, povos indígenas, agricultores urbanos etc. Não podemos permitir que a agroecologia se converta em uma ferramenta a serviço do modelo de produção industrial de alimentos $[\ldots]^{38}$.

Ao contrário da agricultura ou da produção orgânica, que está limitada a uma forma de se produzir alimentos sem a utilização de insumos químicos sintéticos e organismos geneticamente modificados, a agroecologia, conforme discutido nesse artigo, visa, sobretudo, contribuir para esse processo de transformação social. Tal transformação, possui vínculos com outros tipos de mudanças e transformações necessárias, como na ciência, nas formas de se produzir e de se consumir alimentos (sistema alimentar), na relação entre sociedade e natureza, nas relações sociais e de poder, nos objetivos e mecanismos de organização política, no direcionamento das técnicas etc.

\section{Considerações finais}

A agroecologia emerge como uma contraposição ao atual domínio do agronegócio, mas, também, como a busca de materialização de práticas mais justas, sobretudo

\footnotetext{
38 "La agroecología es la respuesta a la pregunta de cómo transformar y restablecer nuestra realidad material en el contexto de un sistema alimentario y un mundo rural que se han visto devastados por la producción industrial de alimentos y sus llamadas Revoluciones Verde y Azul. Consideramos la agroecología como un modo fundamental de resistencia a un sistema económico que sitúa el beneficio económico por delante de la vida. [...] Las soluciones reales a las crisis del clima, de la desnutrición, etc. no vendrán por una conformación al modelo industrial. Hemos de transformarlo y construir nuestros propios sistemas alimentarios locales que establezcan nuevos vínculos campociudad, con base en una producción de alimentos verdaderamente agroecológica por parte de las campesinas y campesinos, pescadores artesanales, pastoralistas, pueblos indígenas, agricultores urbanos, etc. No podemos permitir que la agroecología se convierta en una herramienta al servicio del modelo de producción industrial de alimentos $[\ldots] . "$
} 
para os agricultores familiares/camponeses. Contudo, mais do que evidenciar esse caráter transformador e toda a multidimensionalidade da agroecologia no plano teórico, é pertinente e necessário, no plano da pesquisa, analisar as experiências empíricas, para verificar como a agroecologia tem se materializado (GABOARDI; CANDIOTTO, 2015).

Tais análises são relevantes por dois motivos: 1) para que seja possível separar o joio do trigo, ou seja, identificar aqueles que realmente percebem e lutam por uma agroecologia multidimensional, transformadora e, quem sabe, autonomista e libertária, e aqueles que visam cooptá-la à lógica do poder heterônomo e das relações capitalistas, priorizando sua dimensão econômica; 2) para não se cair em uma romantização da agroecologia, como se ela fosse algo dado e pronto, capaz de solucionar os problemas da humanidade.

A agroecologia é, sobretudo, uma construção social em fase inicial, permeada por uma heterogeneidade de pensamentos e ações, e inacabada. Seu futuro depende de lutas e ações multidimensionais e multiescalares, devido à sua complexidade e aos desafios que a envolvem. Certamente, o Estado, por meio de políticas públicas, dotação orçamentária, capacitação e orientação técnica, entre outras ações, tem sua relevância nesse processo. Contudo, o futuro da agroecologia, depende, sobretudo, da sociedade, de pessoas que percebam sua importância e que estejam comprometidas com seu avanço qualitativo e quantitativo.

Apesar da relevância das análises empíricas, que também devem estar fundamentadas em pressupostos teórico-metodológicos, ao considerar a multidimensionalidade e a interdisciplinaridade que envolvem a agroecologia, as possibilidades em termos de pesquisa e, mais do que isso, as perspectivas de avanços metodológicos, epistemológicos e ontológicos que a agroecologia permite, são aspectos que a tornam complexa e paradigmática.

Nesse sentido, a agroecologia não é somente uma forma de se produzir alimentos orgânicos. Ela se propõe a ser muito mais ampla e profunda! Mas a agroecologia não é um sujeito. Ela é um fenômeno que depende do trabalho, da luta e da própria percepção 
de variados sujeitos sociais sobre o futuro da agricultura, da relação sociedade-natureza e da construção de "novos" ambientes. Assim, mesmo apresentando um potencial para se constituir em um novo paradigma científico, epistemológico e, até ontológico, o futuro da agroecologia depende de como ela será construída, na teoria, mas, principalmente, na prática.

\section{Agradecimentos}

Agradeço ao Conselho Nacional de Desenvolvimento Científico e Tecnológico (CNPq) pela concessão da bolsa de pós-doutorado, e ao Prof. Dr. Marcelo Lopes de Souza (UFRJ) pela supervisão de meu estágio de pós-doutorado.

\section{Referências}

ALTIERI, Miguel. Agroecology: The Science of Sustainable Agriculture. Boulder, CO: Westview Press, 1995.

ALTIERI, Miguel. Agroecologia: a dinâmica produtiva da agricultura sustentável. Porto Alegre: Editora UFRGS, 2000.

ALTIERI, Miguel. Linking ecologists and traditional farmers in the search for sustainable agriculture. Frontiers in Ecology and the Environment, $n^{\circ}$ 2, pp. 35-42, 2004.

ALTIERI, Miguel; TOLEDO, Victor M. The agroecological revolution of Latin America: rescuing nature, securing food sovereignty and empowering peasants. The Journal of Peasant Studies, v. 38, $n^{\circ}$ 3, pp. 587-612, 2011.

AMIGOS DE LA TIERRA. Agroecología: innovaciones para sistemas agrícolas y alimentarios sustentables. Serie Quien se beneficia? 2018. Disponível em: $<$ https://www.foei.org/es/recursos/publicaciones/agroecologia-innovacionespara-sistemas-agricolas-y-alimentarios-sustentables $>$. Acesso em 19/11/2018. 
CAPORAL, Francisco R.; COSTABEBER, José A. Agroecologia: alguns conceitos e princípios. Brasília: MDA/SAF/DATER-IICA, 2004.

CAPORAL, Francisco R.; COSTABEBER, José A. e PAULUS, Gervásio. Agroecologia: matriz disciplinar ou novo paradigma para o desenvolvimento rural sustentável. Brasília (DF), 2006. Disponível em: <http://www.seaembu.org/docs/agroecologia2.pdf>. Acesso em 16/08/2011.

CASADO, Gloria Guzman; GONZALEZ DE MOLINA, Manuel; GUZMAN, Eduardo Sevilha. Introducción a la agroecología como desarrollo rural sostenible. Madrid: MundiPrensa, 2000.

CIDSE. Os princípios da agroecologia: rumo a sistemas alimentares justos, resilientes e sustentáveis. Bruxelas, 2018.

EMBRAPA (Empresa Brasileira de Pesquisa Agropecuária). Marco referencial em Agroecologia. Brasília, DF: Embrapa Informação Tecnológica, 2006.

FRANCIS, Charles A.; LIEBLEIN, Geir; GLIESSMAN, Stephen. R.; BRELAND, T. A.; CREAMER, N.; HARWOOD, R.; SALOMONSSON, Lennart; HELENIUS, Juha; RICKERL, D.; SALVADOR, R.; WIEDENHOEFT, M.; SIMMONS, S.; ALLEN, P.; ALTIERI, Miguel.; FLORA, Cornelia; POINCELOT, R. Agroecology: The ecology of food systems. Journal of Sustainable Agriculture, v. 22, $\mathrm{n}^{\circ}$ 3, pp. 99-118, 2003. DOI: 10.1300/Jo64V22n03_10.

GABOARDI, Shaiane C.; CANDIOTTO, Luciano Z. P. O caráter interdisciplinar e o potencial transformador da agroecologia. In: XI Encontro Nacional da Associação de Pósgraduação e Pesquisa em Geografia, 2015, Presidente Prudente, SP. Anais... Dourados, MS: UFGD Editora, 2015, p. 6744-6757.

GIRALDO, Omar F.; ROSSET, Peter M. La agroecología en una encrucijada: entre la institucionalidad y los movimientos sociales. Guaju, v. 2, nº 1, pp. 14-37, 2016.

GIRALDO, Omar F.; ROSSET, Peter M. Agroecology as a territory in dispute: Between institutionality and social movements. Journal of Peasant Studies, v. $45, n^{\circ} 3, p p$. 545-564, 2018. DOI: 10.1080/03066150.2017.1353496.

GIRALDO, Omar. Ecología política de la agricultura. Agroecología y posdesarrollo. San Cristóbal de Las Casas, Chiapas, México: El Colegio de la Frontera Sur, 2018. 
GLIESSMAN, Stephen. Agroecologia: processos ecológicos em agricultura sustentável. Porto Alegre: Ed. UFRGS, 2001.

GLIESSMAN, Stephen. Agroecology: the ecology of sustainable food systems. CRC Press, Taylor \& Francis, New York, USA, 2007.

GLIESSMAN, Stephen. Defining Agroecology. Agroecology and Sustainable Food Systems, v. $42, \quad \mathrm{n}^{\circ} \quad 6, \quad$ pp. 599-600, 2018. DOI: https://doi.org/10.1080/21683565.2018.1432329.

HECHT, Susanna B. The evolution of agroecological thought. In: ALTIERI, Miguel (org.), Agroecology: the science of sustainable agriculture. Westview Press, Boulder, CO, USA, 1995, p. 1-19.

HIGH LEVEL PANEL OF EXPERTS (HPLE). Sustainable agricultural development for food security and nutrition: what roles for livestock? A report by the High Level Panel of Experts on Food Security and Nutrition of the Committee on World Food Security. Rome, 2016. Disponível em: <http://www.fao.org/3/a-i5795e.pdf>. Acesso em 25/11/2018.

INSTITUTO BRASILEIRO DE GEOGRAFIA E ESTATíSTICA (IBGE). Censo Agropecuário 2017. Disponível em: <https://censos.ibge.gov.br/agro/2017/coleta-censo-agro-2017/estabelecimentos-censo-agro-2017.html>. Acesso em 23/03/2020.

LEFF, Enrique. Ecología y capital: racionalidad ambiental, democracia participativa y desarrollo sustentable. Mexico: Siglo Veintiuno Ed. 1994.

LEFF, Enrique. Agroecologia e saber ambiental. Revista Agroecologia e Desenvolvimento Sustentável. Porto Alegre, v.3, nº 1, pp. 36-51, 2002.

MAZZOLENI, Eduardo M.; NOGUEIRA, Jorge M. Agricultura orgânica: características básicas do seu produtor. Revista de Estudos Rurais (RER). Rio de Janeiro, v. 44, $\mathrm{n}^{\circ} 2$, pp. 263-293, 2006.

MIER, Mateo; CACHO, Terán G.; GIRALDO, Omar F.; ALDASORO, Miriam; MORALES, Helda; FERGUSON, Bruce G.; ROSSET, Peter; KHADSE, Ashlesha; CAMPOS, Carmen. Bringing agroecology to scale: key drivers and emblematic cases. Agroecology and Sustainable Food Systems, v. 42, $n^{\circ}$ 6, pp. 637-665, 2018. DOI: 10.1080/21683565.2018.1443313

MOLINA, Manuel González de. Introducción a la Agroecología. Cuadernos Técnicos SEAE, 2011. 
PETERSEN, Paulo; SILVEIRA, Luciano M. da; FERNANDES, Gabriel B.; ALMEIDA, Silvio G. Método de análise econômico-ecológica de Agroecossistemas. Articulação Nacional de Agroecologia (Brasil). Rio de Janeiro: AS-PTA, 2017.

ROSSET, Peter; ALTIERI, Miguel. Agroecologia: ciência e política. SOCLA, 2018.

SICARD, Tomás L. Agroecología: desafíos de una ciencia ambiental en construcción. In: ALTIERI, Miguel (org.). Vertientes del pensamiento agroecológico: fundamentos y aplicaciones. Medellín, Colômbia: SOCLA, 2009.

SOUZA, Marcelo L. de. Os conceitos fundamentais da pesquisa sócio-espacial. Rio de Janeiro: Bertrand Brasil, 2013.

STÉDILE, João P.; CARVALHO, Horacio M. de. Soberania alimentar: Uma necessidade dos povos. In: BRASIL (Ministério de Desenvolvimento Social e Combate à Fome). Fome Zero: Uma história Brasileira. Brasília, DF, Assessoria Fome Zero, v. 3, 2010, p. 144 a 156.

TOLEDO, Victor. A agroecologia é uma revolução epistemológica. Entrevista de Diana Quiroz. Agriculturas, v. 13, nº 1, pp. 42-45, 2016.

VAN DER PLOEG, Jan D. The drivers of change: the role of peasants in the creation of an agro-ecological agriculture. Agroecología Politica, v. 6, pp. 47-54, 2011.

VAN DER PLOEG, Jan D. Peasant-driven agricultural growth and food sovereignty. The Journal of Peasant Studies, v. 41, $\mathrm{n}^{\circ}$ 6, pp. 999-1030, 2014. DOI: 10.1080/03066150.2013.876997.

WEZEL, Alexander; BELLON, Stéphane; DORÉ, Thierry; FRANCIS, Charles; VALLOD, Dominique, DAVID, Christophe. Agroecology as a science, a movement and a practice. A review. Agronomy for Sustainable Development, v. 29, n 4 , pp. 503515, 2009. DOI: 10.1051/agro/2009004.

WEZEL, Alexander; MIGLIORINI, Paola. Converging and diverging principles and practices of organic agriculture regulations and agroecology. A review. Agronomy for Sustainable Development, v. 37, $\mathrm{n}^{\circ}$ 63, pp. 1-18, 2017. DOI: https://doi.org/10.1007/s13593-017-0472-4. 
Luciano Zanetti Pessôa Candiotto é professor do Programa de Pós-graduação em Geografia da Universidade Estadual do Oeste do Paraná (UNIOESTE), campus de Francisco Beltrão. E-mail: luciano.candiotto@unioeste.br

Artigo enviado em 13/09/2020 e aprovado em 16/11/2020. 